\title{
HARNESSING THE POWER OF LONELINESS: A SOCIAL FUNCTIONAL APPROACH TO LONELINESS AT WORK
}

\author{
Deirdre G. Snyder
}

A dissertation submitted to the faculty at the University of North Carolina at Chapel Hill in partial fulfillment of the requirements for the degree of Doctor in Philosophy in the Kenan-Flagler Business School (Organizational Behavior).

Chapel Hill

2014

Approved by:

Alison R. Fragale

Paul D. Bliese

Michael S. Christian

David A. Hofmann

Shimul Melwani 
(C) 2014

Deirdre G. Snyder

ALL RIGHTS RESERVED 


\begin{abstract}
Deirdre G. Snyder: HARNESSING THE POWER OF LONELINESS: A SOCIAL FUNCTIONAL APPROACH TO LONELINESS AT WORK (Under the direction of Alison Fragale)
\end{abstract}

Much of the current theoretical and empirical research exploring the behavioral outcomes of loneliness is based on chronic loneliness. However, nearly everyone has experienced transient feelings of loneliness throughout their life. In this dissertation I examine the social function of state loneliness and suggest that interpersonal helping is a positive outcome that results from this emotion. By drawing on theories of belonging (Baumeister \& Leary, 1995; Pickett \& Gardner, 2005) attributions (Weiner, 1974; Weiner, 1979), and motivation (Vroom, 1964), I propose an interactive model in which the need to belong and the attributions people make about their loneliness combine to both amplify and attenuate the impact of loneliness on interpersonal helping behavior. This model is tested in three studies with both measured and manipulated state loneliness. Implications for employees and organizations are discussed. 
To Matt, Cassidy, and Nicholas, for bringing laughter and love to my life and inspiring me to do my best every day. 


\section{ACKNOWLEDGEMENTS}

They often say it takes a village to raise a child and I think the same might be said of training a Ph.D student. I would not be here today without the friendship, love, and support of my friends, family, and faculty at Kenan-Flagler. First, I am profoundly grateful for the guidance and support of my advisor, Alison Fragale. Alison embodies so many of the qualities I hope to emulate as I grow as an instructor and researcher. Alison's vision and commitment are extraordinary, and she has been a source of constant insight and support. I hope I have picked up even a little of her ability to see the forest through the trees and ask good questions. Alison always had my back, often fighting for me when I did not even know a fight was brewing, and I am so thankful to have her on my side. She is both a mentor and friend and I hope this is just the beginning of a lifelong partnership.

My work would also not be where it is today without Jeff Edwards. In addition to being an amazing methods instructor, Jeff was also the best mentor teacher a novice classroom instructor could have. I am thankful to both him and his wife Kamie for sharing their house in Chapel Hill and Kure Beach with all of the PhD students. The Edwards are truly a fine example of what it means to be kind and gracious hosts. I hope to return the favor the next time they visit Providence, RI.

I would also like to thank and acknowledge my entire committee-Paul Bliese, Mike Christian, Dave Hofmann, and Shimul Melwani-for challenging me to think deeply about this topic, for brainstorming with me, reading and responding to my emails and drafts with thoughtful 
comments and questions. They have sharpened my thinking and writing and without their help I would not have reached this significant milestone.

I have also been surrounded by wonderful friends over the last five years, some old and some new. I'm thankful for my oldest friend Betsy Hamilton for loving us even though we are now and forevermore Tar Heels. I'm also especially thankful for my colleagues Virginia Kay and Christina Rader. Virginia taught me that there are very few problems in academia that cannot be solved with good chocolate and a bottle of wine, and also showed me, through her example, how generosity in service to others pays dividends beyond compare. I thank Christina for being an honorary member of the family and for inspiring the tradition of welcoming friends for Sunday dinners.

And last, but not least, I am especially grateful to my family. Words cannot express my gratitude to my husband, Matt, for always being my strongest advocate and champion. Simply put, I could not have accomplished this degree if he were not willing to take the leap and leave a life he loved to follow this dream. I am thankful he managed the children, the house, and the dogs when I was absent (physically or mentally); I can think of no better person for the job. I am also incredibly thankful for my children, Cassidy and Nicholas, who always thought I was the best Mom, even when I asked them to be quiet or leave the room so I could read or write (which was often). I am thankful for my sister, Denise Rogers, and my parents, Jan and Ernie Gobeille, for believing in me and cheering me on from the sidelines. I only wish my Dad was alive to see me graduate. I know he'd be proud. 


\section{TABLE OF CONTENTS}

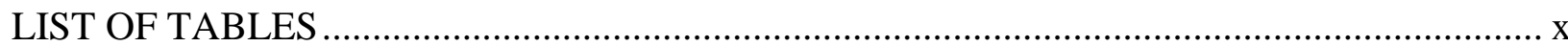

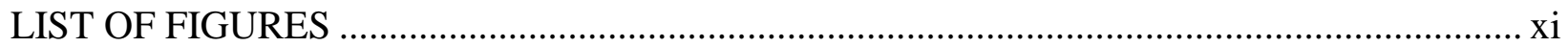

CHAPTER 1: THE SOCIAL FUNCTION OF LONELINESS ............................................... 1

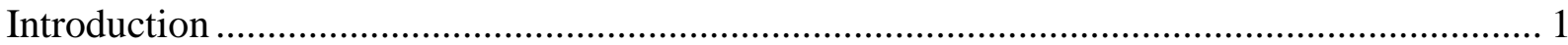

Dimensions of Loneliness and its Social Function .................................................... 6

CHAPTER 2: MODEL AND HYPOTHESIS DEVELOPMENT ........................................ 10

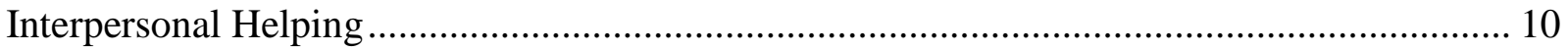

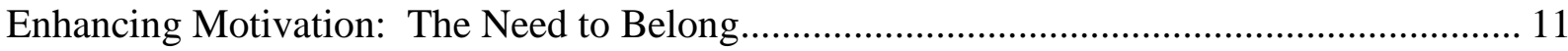

Enhancing Ability: Attributions for Loneliness ............................................................ 14

Interactive Effects of the Need to Belong and Attributions .............................................. 17

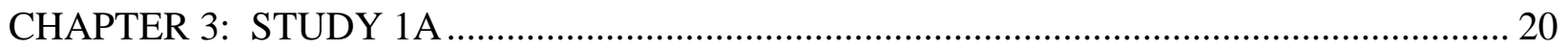

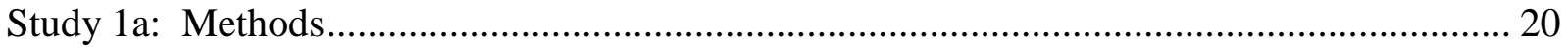

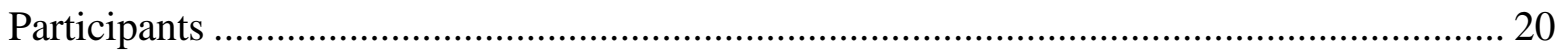

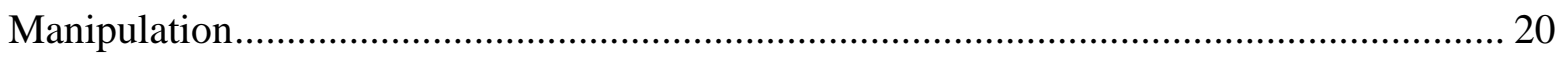

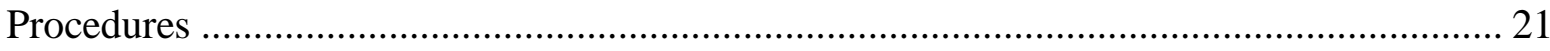

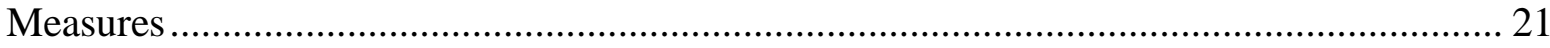

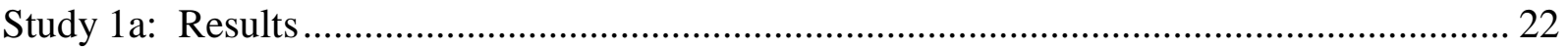




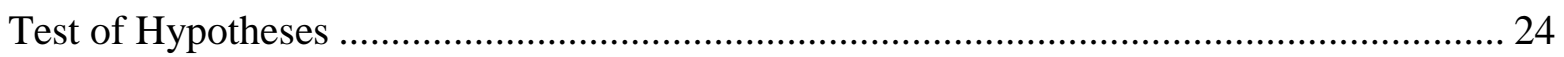

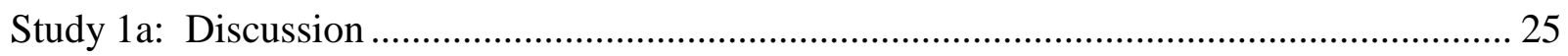

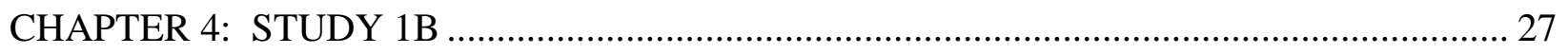

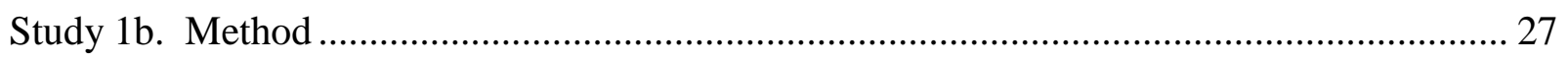

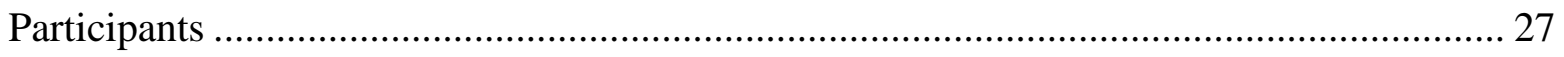

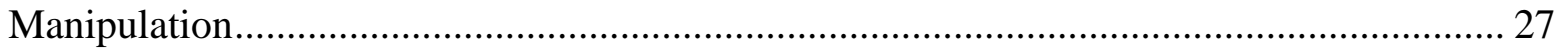

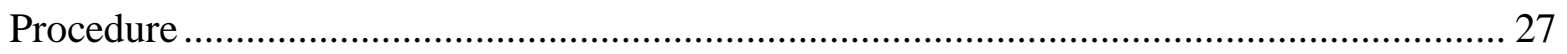

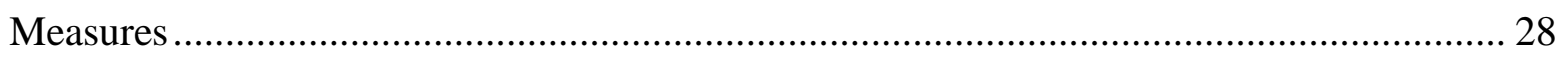

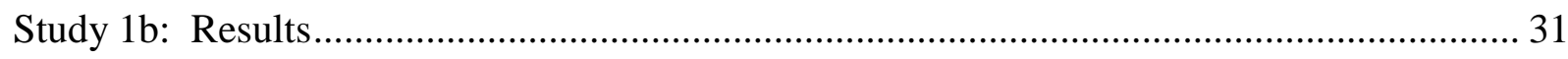

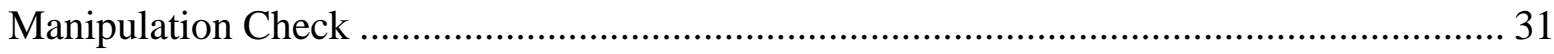

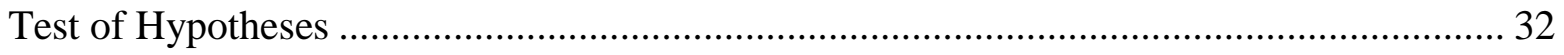

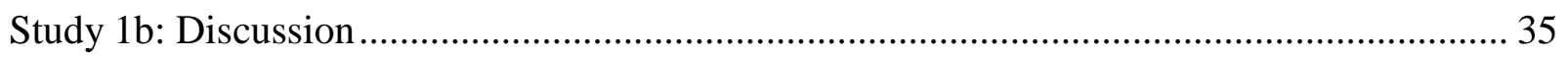

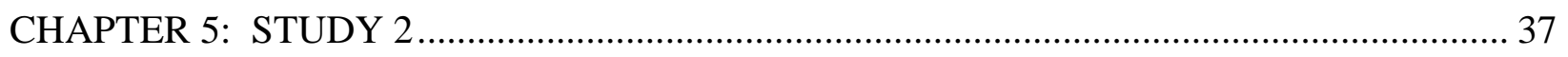

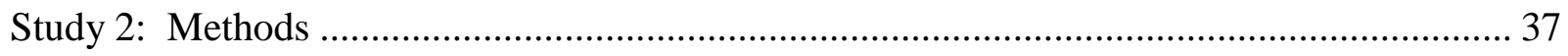

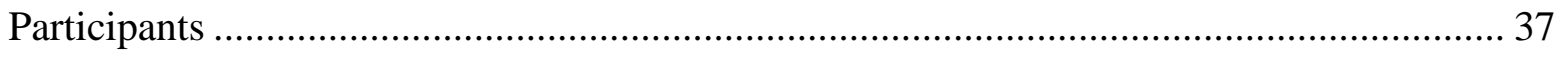

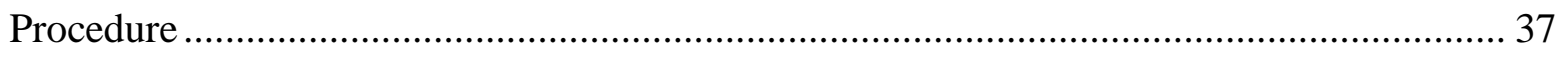

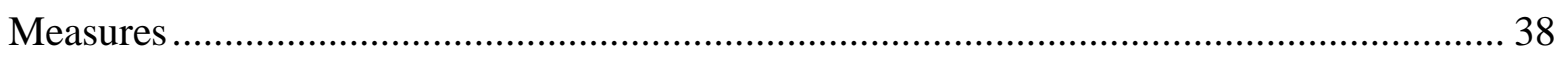

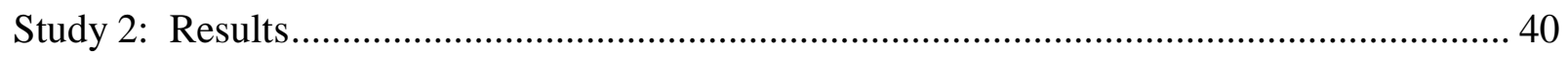

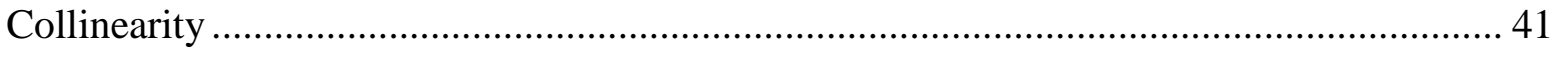




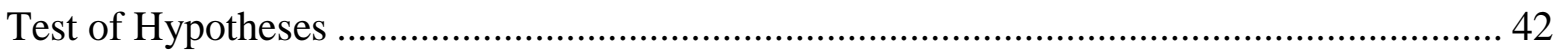

CHAPTER 6: GENERAL DISCUSSION ..................................................................... 47

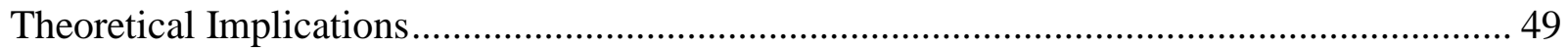

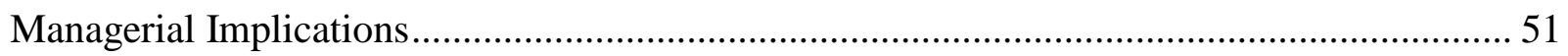

Limitations and Directions for Future Research ....................................................... 52

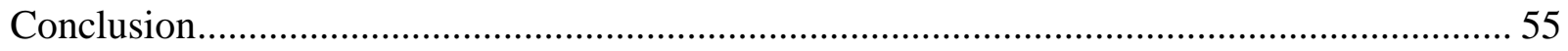

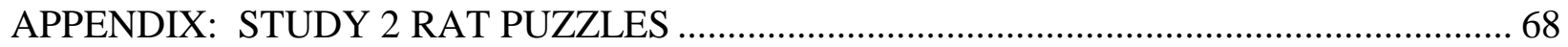

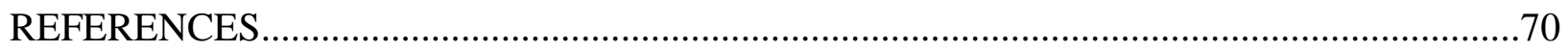




\section{LIST OF TABLES}

Table 1. Means, Standard Deviations, and Correlations among Study 1a Variables..................56

Table 2. Study 1a: OLS regressions to predict number of suggestions ................................57

Table 3. Means, Standard Deviations, and Correlations among Study 1b Variables..................58

Table 4. Study 1b: OLS regressions to predict helping behavior ......................................59

Table 5. Means, standard deviations, and correlations among Study 2 variables......................60

Table 6. Study 2: OLS regression results for the effect of loneliness, the need to belong, and attributions on helping behavior.........................................61

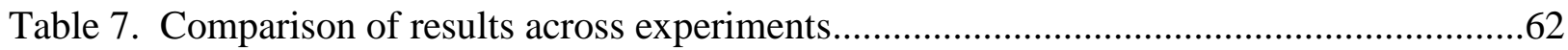




\section{LIST OF FIGURES}

Figure 1. Study 1a: Number of suggestions as a function of loneliness and the need to belong...

Figure 2. Study 1b: Helping behavior as a function of loneliness, the need to belong, and attributions.

Figure 3. Study 1b: Three-way interaction between loneliness, the need to belong, attributions and helping.

Figure 4. Study 2: Two-way interactions between loneliness and the need to belong and attributions.

Figure 5. Study 2: Helping as a function of loneliness, attributions, and the need to belong... 


\section{CHAPTER 1: THE SOCIAL FUNCTION OF LONELINESS}

\section{Introduction}

Loneliness, or the painful emotion felt when individuals perceive a discrepancy between their desired and actual social connections (Peplau \& Perlman, 1982), is on the rise. A recent study conducted by AARP found that 35 percent of adults aged 45 and older indicated they felt lonely, compared with only 20 percent a decade ago (Wilson \& Moulton, 2010). According to the study, loneliness was experienced equally among the sample regardless of race, gender, or education, but was even more prevalent among adults of working age from 45 to 60 .

Changes in society and employment are colliding to create a perfect storm of conditions that may induce feelings of loneliness. The number of Americans living alone has increased to 27 percent in 2013, up from 17 percent in 1970 (Vespa, Lewis, \& Kreider, 2013). Social networks are shrinking as the number of people saying they have no one with whom to discuss important matters nearly tripled between 1985 and 2004 (McPherson, Smith-Lovin, \& Brashears, 2006) and Americans are less likely to attend church, join civic organizations, meet with friends, and socialize with family than in the past 25 years (Putnam, 2000).

The story is no more hopeful at work. Individuals used to feel a sense of security and community that came from long-term employment arrangements. However, changes in these relationships first became apparent in the 1980s when the labor markets became more competitive and technology evolved to replace certain mid-management coordinating and monitoring functions (Capelli, 1999). Employees were no longer guaranteed lifelong employment with the same organization. The economic downturn which began in 2007 
exacerbated these changes and sent a shock through corporate America that led to layoffs and underemployment, and caused others to work multiple jobs or longer hours just to make ends meet. Technological advances have made work inescapable, with email, texting, and smartphones keeping employees connected long past the end of a typical work day. Changes in job design that allow for work-at-home, virtual teams, multiple team membership, and increased travel all have the potential to interrupt one's ability to form and maintain valuable social connections within and outside work. The end result is that adults are short on expendable income and often feel so exhausted at the end of the day they have neither time nor energy to devote to socializing with friends (Bernstein, 2013).

The notion that loneliness may arise from both the home and work environments is consistent with the typology of loneliness first conceptualized by Weiss (1973). Weiss speculated that there were two different dimensions of loneliness, emotional and social, based on the nature of the social connection that was deficient. Emotional loneliness occurs when an individual lacks the bonds that form during intimate attachments such as with a parent, spouse, or romantic partner. Social loneliness is felt when an individual lacks friends or companions, or does not feel part of a larger community or group.

Loneliness has also been differentiated by the duration of the emotion (de Jong-Gierveld \& Raadschelders, 1982; Peplau \& Perlman, 1982; Peplau, 1985). Chronic loneliness, defined as loneliness lasting two years or more (Beck \& Young, 1978), carries serious physical implications and has been linked to a myriad of health-related concerns including: cardiovascular disease (Caspi, 2006), sleep dysfunction (Cacioppo et al., 2002; Hawkley, Preacher, \& Cacioppo, 2010), suicide (Goldmsith, Pellmar, Kleinman, \& Bunney, 2002), and mortality (Shiovitz-Ezra \& Ayalon, 2010), as well as increased depressive symptoms, perceived stress, fear of negative 
evaluations, decreased optimism, lower self-esteem (Hawkley \& Cacioppo, 2010), and cognitive decline (Tilvis, 2004). In fact, a recent meta-analysis of 148 studies and more than 300,000 participants found that loneliness was as strong a predictor of early death as was alcoholism or smoking 15 cigarettes a day (Holt-Lunstad, Smith, \& Layton, 2010).

Chronic loneliness has also been linked to numerous interpersonal disfunctions. For example, the chronically lonely are viewed more negatively in terms of their interpersonal attraction (Lau \& Gruen, 1992; Rotenberg \& Kmill, 1992), have a decreased ability to selfregulate as evidenced through decreased attention (Cacioppo et al., 2000), poorer performance on follow-up tasks (Baumeister, DeWall, Ciarocco, \& Twenge, 2005), and exhibit more aggressive behavior (Twenge, Baumeister, Tice, \& Stucke, 2001). Moreover, chronically lonely individuals are prone to perceive social threats all around them (Cacioppo \& Patrick, 2008) and have problems initiating and maintaining social contact (Horowitz, French, \& Anderson, 1982). The chronically lonely may eventually come to devalue social interaction in general because integration attempts were tried and repeatedly failed (Spitzberg \& Canary, 1985), or because their social skills gradually atrophy through lack of use or motivation (Heinrich \& Gullone, 2006). Thus, lonely people appear to be both less likely to reach out to others and less attractive to be chosen as social partners by others (Cacioppo \& Patrick, 2008).

With so much evidence for the myriad of negative interpersonal and physical outcomes associated with loneliness one might think it is an emotion to be avoided at all costs. However, evolutionary and social psychologists suggest that loneliness serves an adaptive function similar to other aversive human conditions — such as pain, hunger, or thirst — which encourage behavior that promotes survival (Cacioppo, Cacioppo, \& Boomsma, 2014; Cacioppo et al., 2006; Cacioppo, Fowler, \& Christakis, 2009). The survival of the human species is predicated on the 
ability to form relationships between individuals and within groups and Cacioppo and his colleagues argue that loneliness serves to motivate behavior that ingratiates the individual back into the group. However, very little empirical work has been done to test whether loneliness does in fact serve this social function.

This paper seeks to resolve the discrepancy between the negative outcomes associated with chronic loneliness and the functional perspective offered by Cacioppo and colleagues. I suggest that to fully understand the social function of loneliness, we need to examine the impact of state loneliness on behavior. An emotional state is a transient reaction to a specific event or circumstances (Lazarus, 1991a). Nearly everyone has experienced fleeting feelings of loneliness at different times throughout their lives. These transient feelings are captured in the construct of state loneliness, which describes the temporary affective state that arises when an individual recognizes a discrepancy between actual and desired social relations (Peplau \& Perlman, 1982). These temporary feelings of loneliness are generally caused by something in the person or environment that can often be addressed (Young, 1982), but little is known about who is best able to address the emotion quickly or the specific circumstances that might lead to its relief or exacerbation.

A social-functional approach to loneliness is guided by the premise that emotions help individuals respond adaptively to social problems (Keltner \& Haidt, 1999; Keltner \& Gross, 1999). State loneliness should work like other emotions by helping coordinate one's actions in a way that alleviates immediate threats to the individual while bringing about beneficial social consequences for the individual and his or her relationships. One way loneliness might do this is by motivating interpersonal helping behavior. Interpersonal helping promotes closeness to others, fosters group cohesion, and intimacy (Weinstein \& Ryan, 2010). Thus, if state loneliness 
is the spark that alerts an individual that belonging needs are not being met, interpersonal helping might be the salve that ingratiates the individual back into the group.

My dissertation explores the social function of loneliness in order to understand the promise and perils of the emotion. Isolating the behavioral implications of state loneliness can help us understand who is most likely to capitalize on its social function, and who is at risk for spiraling into chronic loneliness if the state feelings cannot be readily addressed. Such knowledge may allow organizations to create interventions that can capitalize on the benefits of loneliness, while at the same time stop temporarily lonely employees from falling into the abyss of chronic loneliness.

In summary, this paper seeks to address three important questions - does loneliness serve a social function; how do state feelings of loneliness impact work-based behavior; and, who is best and least able to capitalize on state feelings of loneliness to improve social connections so that the emotion does not persist to chronic levels. I focus specifically on interpersonal helping as the dependent variable of interest because of its importance to effective organizational functioning, as well as its potential to repair deficient social connections. I explore the impact of loneliness on interpersonal helping with three studies utilizing manipulated and measured state loneliness, as well as three different operationalizations of interpersonal helping.

This paper makes several important contributions. First, I explore the behavioral consequences of state loneliness and explicate the conditions under which loneliness can lead to prosocial, interpersonal helping, an important outcome variable for managers and organizations. Second, I extend theories of belonging (Baumeister \& Leary, 1995) and belonging regulation (Gardner, Pickett, \& Brewer, 2000; Gardner, Pickett, Jefferis, \& Knowles, 2005; Pickett \& Gardner, 2005; Pickett, Gardner, \& Knowles, 2004) by considering when belonging needs can be 
most readily acted upon. Third, I utilize Vroom's ability-motivation interaction hypothesis (Vroom, 1964) to show the impact of loneliness on helping behavior is inspired by both one's motivation to belong to the group as well as one's perceived ability to reconnect with others.

The remainder of this paper unfolds as follows. First, I discuss the social function of loneliness, arguing that state loneliness can lead to interpersonal helping behavior. Second, I discuss two moderators that should impact the value of state-loneliness. Namely, the need to belong should impact one's motivation to utilize helping as a way to ingratiate oneself back into the group, and one's capacity to make unstable attributions for one's loneliness should impact the perceived ability to use helping behavior to change one's current emotional state. Third, I discuss how these two moderators may work in conjunction to amplify or attenuate the degree to which loneliness is positively associated with helping behavior.

\section{Dimensions of Loneliness and its Social Function}

Psychological theories of the self distinguish among the personal self, relational self, and collective self at the individual, collective, and group levels respectively (Brewer \& Gardner, 1996). Loneliness researchers have applied this theoretical framework to the dimensions of loneliness and found that the individual, relational, and collective levels of analysis also characterize people's mental representations of their social connections (Hawkley, Browne, \& Cacioppo, 2005; McWhirter, 1990). Through factor analysis across student and adult samples, researchers found three separate facets within a single overarching loneliness construct (Hawkley et al., 2005).

The first factor is called intimate isolation and is consistent with what Weiss (1973) termed emotional loneliness. It refers to the loneliness one feels when one lacks an intimate bond with another individual who affirms one's value as a person. The second factor is called 
relational isolation and is what Weiss (1973) labeled social loneliness. This factor refers to the perceived closeness of friends and family and involves whether or not the individual perceives there to be a group of like others who can be relied upon for support. The third factor or dimension of loneliness is collective isolation and refers to the perception one has for belonging to a group or social entity that provides meaning beyond the level of the individual (Hawkley et al., 2005). Although Weiss originally differentiated between these types of loneliness, most contemporary loneliness researchers do not make this distinction. Therefore as reported throughout this dissertation, state loneliness refers to the transient occurrence of the emotion in general and I do not differentiate between the social or emotional domains.

We can extrapolate from the factors of loneliness to predict that individuals might feel lonely at work when they lack a friend or close colleague or when they lack connection to their work group or larger organizational entity. In fact, work group cohesion was the single largest predictor of loneliness at work: those who expressed less work group cohesion were more lonely, even after controlling for gender, marital status, race, and organizational level (Bell, Roloff, Van Camp, \& Karol, 1990). Moreover, chronically lonely employees also felt less affective commitment to their organization which negatively impacted task, team role, and relational performance (Ozcelik \& Barsade, 2011).

While this research suggests negative outcomes to feeling lonely at work as manifest through decreased work group cohesion and performance, others suggest that loneliness is a driving force that motivates people to initiate social interactions (e.g., Sullivan, 1953; R. S. Weiss, 1973). This process is described in the theory of belonging regulation which proposes a regulatory system that is dedicated to maintaining a stable and acceptable level of social inclusion (Gardner et al., 2000; Gardner et al., 2005; Pickett \& Gardner, 2005; Pickett et al., 
2004). Gardner and colleagues suggest that loneliness serves as the trigger that causes one to recognize that belonging needs are not being fulfilled and encourages the individual to monitor the environment for cues and opportunities for inclusion. Individuals experiencing loneliness then use these cues to initiate and facilitate social inclusion.

Drawing from this theory, I propose that loneliness may manifest in functional behavior in several ways. First, feelings of loneliness alert individuals that their social connections are at risk and motivate behavior that will help restore valued social connections (Cacioppo et al., 2014; Pickett \& Gardner, 2005). Second, if one is shunned from the group for having broken group norms or acted in selfish ways, feelings of state loneliness can serve as punishment. In this way, state loneliness might encourage people to act in ways that can restore their image by promoting an other-orientation (Cialdini \& Kenrick, 1976) which proves one's desire to belong to a valued social group. Third, state loneliness may promote behaviors that foster work group cohesion and reinforce affective commitment. From an evolutionary perspective, humans are adapted for group and communal living. Individuals who belong to a secure group receive food, protection, and shared resources. Moreover, through situational learning people are often able to see which behaviors ingratiate someone into a group as compared to those that lead to exclusion (Bandura, 1986; 1977) and groups consisting of members who feel secure and work together are more efficient, better able to develop creative solutions, adapt to new challenges, and outperform other less cohesive groups (Beal, Cohen, Burke, \& McLendon, 2003). Thus, state loneliness can help can remind people of the importance of group membership and foster behavior that reinforces common goals and an affinity for members. In this way, state loneliness may serve as the spark that both increases awareness that an individual's social connections are at risk or on 
The periphery while also encouraging the person to utilize behaviors that have been known to build rapport, such as interpersonal helping. 


\section{CHAPTER 2: MODEL AND HYPOTHESIS DEVELOPMENT}

\section{Interpersonal Helping}

In general, helping behavior includes any effort that has as its goal improving the wellbeing of another person, including giving a gift, providing resources to accomplish a task, or even making a donation (Dovidio, Piliavin, Schroeder, \& Penner, 2006). From an organizational standpoint, interpersonal helping behavior occurs when an individual voluntarily helps others with work-related problems in order to accomplish tasks or attain goals and is an important form of organizational citizenship behavior (Borman \& Motowidlo, 1997; George \& Jones, 1997; George \& Brief, 1992; Podsakoff, MacKenzie, Paine, \& Bachrach, 2000). Interpersonal helping promotes closeness to others, fosters group cohesion, and intimacy (Weinstein \& Ryan, 2010) which may all address state feelings of loneliness.

Theories of social exchange propose that some relationships evolve over time into trusting, loyal and mutual commitments and that one of the best known ways to build relationships is through reciprocity (Blau, 1964). When an individual feels loneliness at work, the person might reach out to colleagues with offers of help and assistance. By helping another individual, the person experiencing loneliness is in essence planting the seed for a future exchange and building a perceived obligation on the part of those helped to reciprocate behaviors to those to whom they feel indebted. Further, individuals tend to reciprocate with behaviors that have been shown to be valued (Hofmann, Morgeson, \& Gerras, 2003). When an individual has proven to be particularly helpful and supportive, it is likely that a colleague will repay that obligation by returning the favor and helping at a future date. Thus, individual level reciprocity promotes cooperative behavior between two people and can help build a friendship based on 
mutual trust and reciprocated, supportive behavior. Ultimately, this may remedy feelings of loneliness caused by perceived gaps in social connections.

However, it is not just norms for reciprocity that lead to helping behavior. People often help others even in cases in which the beneficiary is a stranger they never expect to see again (e.g., returning a wallet, donating blood, posting online product reviews). Through the process of social learning, people observe others' helping behavior and learn that there are social rewards for helping (Bandura, 1986; 1977). Moreover, there is ample evidence that people might help others in order to improve their bad mood (e.g., Baumann, Cialdini, \& Kendrick, 1981; Cialdini, Darby, \& Vincent, 1973b). In this way, helping serves as a reinforcer that makes them feel good, which may serve to reduce the negative feelings of loneliness. Finally, a person who feels lonely might also recognize the need to subjugate self-interest in order to help others accomplish team goals. By putting aside individual goals and helping others, one proves one's value to the collective, and as part of a valued group, members feel more responsible for working on behalf of the community (Fiske, 2004). In fact, organizational identification and internalization have been linked to increased prosocial behavior and decreased turnover intent (O'Reilly \& Chatman, 1986). By working toward the betterment of the group through helping behavior, an individual enhances his or her self-worth and can decrease state loneliness by reaffirming membership in a valued social group.

This leads to the following hypothesis:

Hypothesis 1. State loneliness is positively related to interpersonal helping behavior.

\section{Enhancing Motivation: The Need to Belong}

Establishing and maintaining secure social relationships is a core motive in human

psychology (Baumeister \& Leary, 1995; Maslow, 1943; Ryan \& Deci, 2000) and is critical for a 
subjective sense of well-being (Baumeister, 1991). Baumeister and Leary (1995) write that, "human beings have a pervasive drive to form and maintain at least a minimum quantity of lasting, positive, and significant interpersonal relationships" (p. 497) and that fulfilling the need to belong requires frequent interaction with others in order to create long-term, stable relationships based on mutual concern (Baumeister \& Leary, 1995).

Although the need to belong is essential for our well-being it not universally expressed in all humans. Individuals high in the need to belong are characterized by strong needs for acceptance, strong negative reactions to anticipated exclusion or rejection, and are more preoccupied about their level of social regard (Leary, Kelly, Cottrell, \& Schreindorfer, 2007). Notably, those high in the need to belong do not necessarily lack social inclusion, rather, they require a higher threshold of social connections to fulfill their belonging goals (Pickett et al., 2004). On the other hand, individuals with a low need to belong can be satisfied with relatively few social connections, care less about being included in the group, and are less concerned with the group's perceptions (Kelly, 2001).

Baumeister \& Leary's (1995) belongingness hypothesis suggests that regardless of the level of the belonging need, real or perceived discrepancies in one's belongingness status will produce an emotional response: positive when one's belonging needs are fulfilled and negative when they are not. However, a direct connection between the need to belong and loneliness has not been consistently supported. In an effort to establish the construct validity of the need to belong scale, Leary, Kelly, Cottrell, \& Schreindorfer (2013) found no relationship between the need to belong and loneliness among two university samples $(n=205, r=.02$, and $n=325, r=-$ 0.03), yet found the variables correlated at .25 among an adult MTurk sample. However, different measures of loneliness were used: Russell et al. (1980) for the university sample, and 
Hughes, Waite, Hawkley \& Cacioppo (2004) for the MTurk sample. Others have also found a correlation of .28 among an adult sample using the Russell (1996) UCLA Loneliness Scale (Version 3) (Mellor, Stokes, Firth, Hayashi, \& Cummins, 2008). It could be that the college student population did not feel lonely because the students were better at fulfilling their belonging needs due to the relatively easy access to a large pool of possible social connections, while the adult population felt a greater degree of unmet belonging goals such that those both high and low on the need to belong indicated they felt lonely.

One thing that seems certain is that it is not just the trait level of the need to belong that induces loneliness, but rather the degree to which one's satisfaction with current social connections matches the level that is necessary in order to satiate belonging goals. Loneliness should arise when belonging needs are not being met, regardless of whether the individual is high or low on the need to belong.

However, the motivational tendencies associated with the need to belong might differ based on whether a person is currently feeling lonely and how important the need to belong is for their well-being. Emotion theorists suggest that the intensity and motivational quality of an emotion is tied to the importance of the goal (Lazarus, 1991b). This implies that those for whom belonging goals are more important (i.e., who have a high need to belong) will be more motivated to pursue activities that can repair or replace social connections than those for whom the goal is less important.

Thus, when faced with a deficit in belonging needs, state-lonely individuals with a high need to belong should show an increase in goal-directed activity aimed at forming relationships. In fact, individuals with a high need to belong were found to be more attentive and accurate in decoding social cues such as vocal tone and facial emotion (Pickett et al., 2004) and showed a 
heightened sensitivity to social information including verbal and non-verbal social cues (Gardner et al., 2005). This suggests that those with a high need to belong paid closer attention to social cues that may have helped them detect opportunities for social inclusion.

Thus, I propose that the effect of loneliness on helping behavior is likely to be even stronger among people who have a high need to belong. This is because state-lonely individuals with a high need to belong feel an increased urgency and motivation to build connections to maintain their well-being, while at the same time are more attune to information that will help them navigate the social environment successfully. They may be particularly adept at sensing opportunities to help others as a way to establish social contact and build long-term positive relationships. In contrast, state-lonely individuals with a low need to belong may be less motivated to help others because the goal of reconnecting is less important to them and at the same time may be less able to notice helping opportunities within their social environment.

Hypothesis 2: The effect of state loneliness on interpersonal helping will be moderated by the need to belong, such that state loneliness is more strongly related to interpersonal helping when the need to belong is high rather than low.

\section{Enhancing Ability: Attributions for Loneliness}

Bernard Weiner developed a theory of motivation and emotion based on the causal ascriptions people use to explain the success or failure of important goals (Weiner, 1974; Weiner, 1979). The theory is based on the importance of achievement strivings for well-being goals and suggests that three causal dimensions combine to both create affect and motivate behavior. Attributions for locus of control vary from internal to external and relate to whether factors resided inside the person or within the environment. Attributions regarding stability range from stable to unstable, and describe one's expectancy about the factor remaining in the 
future. Controllability ranges from controllable to uncontrollable and describes the degree to which the individual can control the factor.

Consistent with Weiner's framework, researchers have investigated causal attributions for loneliness and found that they fall along two dimensions: stable-unstable and internal-external (Michela, Peplau, \& Weeks, 1982; Peplau, Russell, \& Heim, 1979). Stable causes are those which are relatively unchanging and can be internal, such as physical unattractiveness or having an unpleasant personality; or external, such as other people having established groups that do not welcome new members readily. Unstable causes can likewise be internal, such as the person's lack of effort to meet new people or lack of knowledge; and external, such as having a lack of opportunities to socialize.

Emotions and perceptions about attributions aggregate over time (Weiss \& Cropanzano, 1996), which means if state feelings of loneliness cannot be readily resolved, the person will come to think of the causes as a stable element of his or her environment. One study had college freshmen rate their degree of loneliness as well as the importance of 13 different causes of loneliness at two weeks, seven weeks, and seven months into their first year. Cutrona (1982) compared the chronically lonely group (lonely at all three times) with the transiently lonely (lonely at two weeks, but not at seven months) and found that students who remained lonely all year were more likely to attribute their feelings to stable causes such as being too shy, their personality, fear of rejection, and not knowing what to do to start a relationship, than their transiently lonely counterparts. Thus, chronically lonely people tended to blame their loneliness on their own enduring traits more so than others who started out lonely, but felt connected by the end of their freshman year. 
According to attribution theory, how a person interprets the interpersonal failure impacts the success expectancies and coping strategies for resolving the failure (Abramson, Seligman, \& Teasdale, 1978; Bandura, 1977; Weiner, 1979). Lonely individuals who attribute an interpersonal failure to stable causes, such as a lack of ability, will be less hopeful about future successes and less sure of their ability to repair their social connections than those who attribute the failure to unstable causes, such as a lack of effort (Michela et al., 1982; Peplau et al., 1979). For example, if a person who feels lonely has tried repeatedly to reach out to others and been unsuccessful, the person will be more likely to attribute the loneliness to stable causes and will be less sure of his or her ability to proactively cope with the emotion. In support of this, one study found that lonely students who attributed their feelings to stable personality characteristics (e.g., low ability, personality traits) rather than to unstable factors (e.g, lack of effort, use of ineffective strategies) were less effective in an interpersonal follow-up task (Anderson, 1983).

On the other hand, if the individual has a past history of successfully addressing the feelings of loneliness as they occur, he or she is more likely to view the causes as unstable, and will have greater expectancies in his or her ability to repair the interpersonal belonging failure in the future. Those with unstable attributions should have greater expectancies in their ability to reconnect with others and, thus, be more likely to use proactive coping mechanisms. For example, individuals who made unstable attributions about the cause of their loneliness were more likely to indicate they would go to a party, or doing something else proactive to meet new people (Peplau et al., 1979).

This leads to the following pair of hypotheses:

Hypothesis 3a. The effect of state loneliness on interpersonal helping will be moderated by the attributions one makes for loneliness, such that state loneliness 
will be positively related to interpersonal helping when attributions are unstable rather than stable.

Hypothesis 3b: State loneliness will be negatively related to interpersonal helping when attributions are stable rather than unstable.

\section{Interactive Effects of the Need to Belong and Attributions}

Thus, I propose that the impact of state loneliness on helping behavior is due in part to both the need to belong and the attributions people make for the cause of their loneliness. This suggests that in order for a state-lonely person to recognize and use helping behavior as a remedy for their loneliness, they must have either the motivation (i.e., the need to belong) or the ability (i.e., unstable attributions). But, what if they have both motivation and ability, would they be even more likely to help? And, are those who lack both the least likely to capitalize on opportunities for helping as a mechanism towards reinclusion?

The impact of the ability-motivation interaction was discussed by Vroom (1964) who suggested that performance improvements would be most obvious when motivation was high because that was when the variability of individual differences in ability would be more meaningful. Applying this theory to the loneliness-helping link implies that individuals will be the most helpful when they hold unstable attributions for their loneliness such that they believe there is something they can do to address or remedy their failed social connections (i.e., they believe they have the ability to help) and when are motivated to reconnect with the group (i.e., have a high need to belong). This suggests a three-way interaction between loneliness, the need to belong and attributions on interpersonal helping.

I propose that one's need to belong and the attributions made for one's loneliness combine to amplify or attenuate the effects of loneliness on helping behavior. Specifically, 
lonely individuals with a high need to belong and who make unstable attributions should be more helpful than others who make unstable attributions because a) they are motivated to be part of the group and b) feel they can do something about their feelings of loneliness. It is logical that these individuals might utilize helping behavior as a way to improve their self-image as someone who warrants group inclusion and thereby ingratiate themselves back into the group or possibly as a means to improve their negative mood. On the other hand, well-connected others (i.e., the notlonely) with a high need to belong and unstable attributions feel comfortable with their social connections. They want to be part of the group and in fact, feel that they are. These individuals should be less motivated to help either because they are already part of the group or because there is no need to repair a negative mood.

I suggest that the opposite is also true: Lonely individuals with a low need to belong who make stable attributions should be less likely to help than similar others who are not-lonely. This is because they see no recourse for their loneliness and have little desire to be part of the group anyway. Thus, they are unlikely to see helping as a remedy to their lonely feelings. On the other hand, not-lonely individuals who make stable attributions should feel comfortable with their social connections and expect that not to change. These socially-confident others should be more likely to help because either because they realize that helping others has led to their preferred social standing or because they see helping as part of the social norm for group inclusion.

This leads to the following hypotheses:

Hypothesis 4a: Among those who make unstable attributions, lonely individuals with a high need to belong will be more helpful than not-lonely people with a high need to belong. 
Hypothesis 4b: Among those who make stable attributions, lonely individuals with a low need to belong will be less helpful than not-lonely people with a low need to belong. I test these hypotheses in a series of three studies. Study 1a establishes the positive relationship between loneliness and interpersonal helping in a student sample utilizing an established manipulation of loneliness (Wildschut, Sedikides, Arndt, \& Routledge, 2006) and shows the need to belong as an important moderator. Study $1 \mathrm{~b}$ utilizes the same loneliness manipulation and student sample and tests both the need to belong and attributions as moderators with a different helping task. Study 2 tests the model across a nationwide sample of adults using measured state loneliness and a different behavioral measure of helping. 


\section{CHAPTER 3: STUDY 1A}

\section{Study 1a: Methods}

\section{Participants}

Eighty-one individuals (43 males) from a southeastern university participated in the study for credit as part of an introductory organizational behavior course. The mean age was 20.77 and sixty-nine percent were white. Participants were randomly assigned to one of two loneliness conditions (high vs. low).

\section{Manipulation}

This study utilized an experimental manipulation of loneliness (Wildschut et al., 2006; Zhou, Sedikides, Wildschut, \& Gao, 2008) in which participants indicated whether they agreed or disagreed with each of 15 statements drawn from the UCLA Loneliness Scale (Russell, 1996). Statements administered to the high loneliness group were structured so as to elicit agreement by utilizing a stem of, "I sometimes" as in "I sometimes feel alone." Those in the low loneliness group responded to items structured to elicit disagreement by using the stem, "I always" as in "I am always a bit short of companionship." Participants were then given an accurate count of how many of the 15 items they had agreed to, but presented with false feedback on how their results compared to peers. Participants in the high loneliness condition were informed they were in the

$62^{\text {nd }}$ percentile of the loneliness distribution and were thus, more lonely than the average student at their university. Participants in the low loneliness condition were informed they were in the $12^{\text {th }}$ percentile of the loneliness distribution, and thus, less lonely than the average student. To reinforce this manipulation, participants were instructed to spend a few minutes after they 
received their feedback to write about why they thought they were more (or less) lonely than average.

\section{Procedures}

Between 6 and 12 individuals participated in each experimental session. As participants arrived, they were seated in one of two laboratory rooms, each at individual study carrels with computer terminals. The study was conducted online using Qualtrics. After signing an electronic consent form, participants completed the need to belong scale (Leary et al., 2013), the loneliness manipulation and manipulation check of state emotions. Participants were then told that they were to provide feedback on a fellow undergraduate student's cover letter that had been provided by the University's business communication center and was an actual letter a student intended to send to a prospective employer. Participants were told that their comments would be sent to the student and were presented with an open-ended text box in which to offer their

feedback. Immediately following the cover letter task, students responded to a nine-item measure of task engagement (Rich, Lepine, \& Crawford, 2010). Finally, students were debriefed about the loneliness manipulation and false feedback before working on an unrelated study.

\section{Measures}

Unless otherwise indicated, all items used a 7-point scale $(1=$ strongly disagree and $7=$ strongly agree).

Need to Belong. The need to belong (Leary et al., 2013) was assessed with a seven-item measure $(\alpha=.82)$ that included, "I have a strong need to belong", "I try hard not to do things that will make other people avoid or reject me", and "My feelings are easily hurt when I feel that others do not accept me." 
State-Emotions. Immediately following the manipulation, participants were asked to respond to the degree to which they were feeling eight emotions in the present moment on a 5point scale $(1=$ not at all and $5=$ extremely $)$. The words served as the primary manipulation check and included: lonely, isolated, connected, befriended, happy, cheerful, sad, and blue.

Task Engagement. Following the cover letter task participants were asked to reflect on their engagement in the task by responding to nine items of an engagement scale that was adapted from (Rich et al., 2010). The measure included items on physical engagement (e.g., "I exerted my full effort on this task"), emotional engagement (e.g., "I am proud of the contributions I made to this letter"), and cognitive engagement (e.g., "I paid a lot of attention to this task"). A composite score was created for overall task engagement by averaging the responses to the nine items $(\alpha=.96)$.

Interpersonal helping. Helping was assessed by the number of unique suggestions that each participant entered into an open-ended text box within the survey software. The author and a second rater blind to the conditions each independently counted the number of ideas presented in each response. If a sentence included more than one unique idea, each idea was counted independently. Likewise, if a sentence included a statement of opinion (e.g., "This is a good letter"), but did not provide constructive feedback, it was not to be counted. The two raters achieved good consistency $\left(\mathrm{ICC}_{2}=.951\right)$ and agreement $\left(\mathrm{ICC}_{2}=.947\right)$ that were well within conventional guidelines (LeBreton \& Senter, 2008). Thus, the ratings were averaged to create a single measure of the number of suggestions for each participant.

\section{Study 1a: Results}

Recall that participants in the high loneliness condition were told they were in the $62^{\text {nd }}$ percentile for loneliness at their university. In order for this feedback to be credible, participants 
needed to agree to more than one of the statements in the modified loneliness scale. One participant agreed with zero statements and another agreed to only one. The feedback was likely not credible for these two participants and they were removed from future analyses. Likewise, participants in the not-lonely condition who agreed to too many of these statements would have likely found it hard to believe that they were only in the $12^{\text {th }}$ percentile. Three participants agreed to four or more of the statements and were likewise removed. Thus, five participants were removed because the false feedback manipulation was not credible based on their actual responses. An additional three participants were removed after noting their suspicion of the veracity of the cover letter task. The following analyses are conducted with the remaining 73 participants.

Table 1 provides the means, standard deviations, and correlations between the Study 1a variables. There is a positive relationship between loneliness and the number of suggestions $(\mathrm{r}=$ $.31, p<.01)$ and there is no significant relationship between state loneliness and the need to belong $(\mathrm{r}=.11, p>.05)$.

\section{Manipulation Check}

The effectiveness of the loneliness manipulation was assessed in two ways. First, as intended, participants in the lonely condition agreed to more items than those in the not-lonely condition $\left(\mathrm{M}_{\text {lonely }}=8.18\right.$ vs. $\left.\mathrm{M}_{\text {not-lonely }}=.46, F(1,72)=126.12, p<.000\right)$. Next, I compared the results on state emotions by condition. Participants in the lonely condition $(\mathrm{M}=1.68)$ reported feeling more lonely than those in the not-lonely condition $(\mathrm{M}=1.29), F(1,72)=5.499, p<.05$. Participants in the lonely condition also reported feeling marginally more isolated $(\mathrm{M}=1.68)$ than those in the not-lonely condition $(\mathrm{M}=1.34), F(1,72)=3.418, p=.069$. There were no other significant differences in the other state emotions, indicating that the manipulation affected 
feelings of loneliness and isolation primarily, but not sadness (sad, blue), or happiness (happy, cheerful), or connectedness (connected, befriended).

\section{Test of Hypotheses}

Table 2 provides the results of the regression analyses for the main effect of loneliness on interpersonal helping as well as the test of moderation for the need to belong. I regressed the number of helpful suggestions on the loneliness condition, the centered need to belong and the interaction between loneliness and the need to belong. There was a main effect of loneliness on the number of suggestions $\left(\mathrm{M}_{\text {lonely }}=5.34, \mathrm{M}_{\text {not-lonely }}=3.86, b=.707, t(69)=2.68, p<.01\right)$.

In addition, this main effect was qualified by an interaction between loneliness and the need to belong that did not reach conventional levels of significance $(b=.468, t(69)=1.798, p$ $=.077$ ). However, I conducted a simple slopes analysis using the process suggested by Aiken and West (1991) and as can be seen in Figure 1, participants were significantly more helpful when they were in the lonely condition and had a high need to belong. I found significant differences in the conditional effect of loneliness on helping behavior at the mean $(b=.707$, SE $=.264, t(69)=2.677, p=.009)$ and at one standard deviation above the mean $(b=1.19, \mathrm{SE}=$ $.382, t(69)=3.12, p=.003)$. I also tested for the regions of significance analysis using the Johnson-Neyman technique (Johnson \& Neyman, 1936) by using an SPSS macro developed by Hayes and Matthes (2009). This technique finds the value of the moderator variable for which the ratio of the conditional effect to its standard error is equal to the critical $t$ score. The conditional effect of the need to belong on loneliness transitioned to significance at a need to belong score of $-.33(\mathrm{~b}=.44, \mathrm{SE}=.2762), t(69)=1.995, p=.05)$. Specifically, this analysis

revealed that for need to belong scores above -.33 , the lonely group displayed a significantly larger increase in helping behavior relative to the not-lonely group. Thus, I found support for 
Hypothesis 1, predicting a main effect of loneliness on helping and for Hypothesis 2, predicting a moderating effect of the need to belong, which was significant for levels at slightly below the mean and higher.

Loneliness is experienced as a negative emotion, and research on emotions suggests that negative emotions inspire higher levels of systematic processing than positive emotions (Schwarz, 2001; Tiedens \& Linton, 2001). Thus, the increased number of suggestions made by lonely people could be an artifact of increased cognitive processing resulting from negative emotions. To rule this out as a mechanism for increased helpfulness, I tested task engagement as a mediator of the relationship between loneliness and the number of suggestions.

While task engagement did significantly predict the number of suggestions $(b=.767$, $t(63)=4.51, p<.01)$, loneliness did not significantly affect task engagement $(b=.07, t(63)=$ $.367, p>.05$ ), and including task engagement in the model did not significantly reduce the impact of loneliness on the number of suggestions ( $\mathrm{b}$ reduces from $=.678$ without task engagement to $\mathrm{b}$ $=.622$ with task engagement in the model). In addition, participants in the lonely condition did not spend any longer on the task (as measured by seconds typing in the open-ended box) than participants in the not-lonely condition $\left(\mathrm{M}_{\text {not-lonely }}=332.96, \mathrm{M}_{\text {lonely }}=364.99, F(1,72)=.473\right.$, $p>.05)$, nor did they use more words (as counted by Excel) $\left(\mathbf{M}_{\text {not-lonely }}=98.91, \mathbf{M}_{\text {lonely }}=103.42, F\right.$ $(1,72)=.101, p>.05)$.

\section{Study 1a: Discussion}

The findings of Study 1a extend our current understanding of the impact of loneliness and interpersonal helping in several ways. First, this study reveals a direct connection between loneliness and interpersonal helping. Contrary to prior research indicating those with chronic loneliness may be more likely to withdraw (Rubenstein \& Shaver, 1982), this research provides 
evidence that state loneliness can actually spur people to action in a meaningful and positive way. Second, it reveals the importance of the need to belong as a moderator. Lonely individuals are more likely to help when they have an average or above average need to belong. This suggests that motivation plays an important role in how state loneliness impacts helping behavior. Only those lonely individuals who were motivated to belong to a group were more likely to help others. 


\section{CHAPTER 4: STUDY 1B}

The objective of Study $1 \mathrm{~b}$ was to add stable attributions as a potential moderator and test for a three-way interaction between loneliness, the need to belong, and attributions. This experiment uses the same manipulation as in Study 1a and introduces a new dependent variable that has been used successfully in past research, albeit as a task to measure interpersonal deviance (Christian \& Ellis, 2011).

\section{Study 1b. Method}

\section{Participants}

The sample included seventy-nine undergraduate business students who were enrolled in an organizational behavior class at a large university in the southeastern United States and participated in exchange for course credit. The average age of participants was 21.16 (s.d.= 3.10), 43 percent were women, and 76 percent identified as non-Hispanic white.

\section{Manipulation}

This study used the same loneliness manipulation as described in Study 1a in which participants were randomly assigned to one of two versions of a modified UCLA Loneliness scale (Russell, 1996), were provided with false feedback about their degree of loneliness, and then wrote about the reasons for their loneliness in an open-ended essay prompt (Wildschut et al., 2006; Zhou et al., 2008).

\section{Procedure}

Between 4 and 8 individuals participated in each experimental session. As participants arrived, they were seated at an individual study carrel with a computer terminal. The study was 
conducted online using Qualtrics. After signing an electronic consent form, participants completed basic personality measures including the same scale for the need to belong as used in Study 1a (Leary et al., 2013), responded to the modified UCLA Loneliness scale and received false feedback, and reinforced the manipulation via the writing task consistent with Study 1a. Next, participants responded to a measure of state emotions and then answered items from the Revised Causal Dimension scale (McAuley, Duncan, \& Russell, 1992) in order to measure the attributions the participant made for their loneliness. Finally, participants logged onto temporary email accounts set up for each participant before the session and responded to three emails from undergraduate students (Christian \& Ellis, 2011). Participants then returned to the Qualtrics survey to provide demographic information, and finally were told they had completed the study and could leave the lab. Participants were debriefed about the loneliness manipulation by email at the end of the day.

\section{Measures}

Need to Belong. The need to belong (Leary et al., 2007) was assessed with the same seven-item measure in Study 1a $(\alpha=.814)$.

State Loneliness. Immediately following the false feedback, participants were asked to rate their current level of emotions relative to their emotions when they first came to the study session with several bi-polar scales including sadder-happier, lonely-connected, abandonedsupported, depressed-elated, excluded-included. Items were anchored such that higher scores indicated more negative emotion. For example, the lonely item was anchored as follows: $7=$ Much more lonely, $4=$ No change, and $1=$ Much more connected .

Attributions. Attributions $(\alpha=.615)$ were measured using the revised causal dimension scale (McAuley et al., 1992). Participants were asked to characterize the reasons for their 
loneliness contained in their essays with three items arranged on a seven-point bipolar scale: "permanent to temporary," "stable over time to variable over time," and "unchangeable to changeable." Responses to these three items were averaged and higher values indicate more stable attributions (i.e., permanent, stable over time, and unchangeable) while lower values indicate unstable attributions (i.e., temporary, variable over time, and changeable).

Interpersonal Helping. Interpersonal helping was assessed with an email task that was adapted from Evans \& Gilliland (2006) and utilized in Christian \& Ellis (2011). Participants were told that the business school was experimenting with a mentorship program and they were being asked to test out a new protocol in which undergraduates interested in the business school emailed questions to current upper-classman business school students. Participants were told that this was an important task because they could give younger students a preview of the business school and help them make their decision about whether or not to apply. Participants accessed these emails via a temporary email account that contained three messages from prospective students and were told to respond however they felt appropriate. Although participants were led to believe these emails were from real students, all participants responded to the same three fictitious messages:

(a) Dear [Business School] Mentor, I am just curious about the classes they offer. I am planning on paying my own way thorough [sic] college and I am wondering if there are any classes that are a waste of my time and money there and if so why? Thanks-Raj.

(b) I am interested in both music and business. Do you have an opinion on whether it would be better to do a business management major and a music minor, or a music major and a business minor? I would ultimately like an A\&R job in the recording industry. John Wycof 
And

(c) Are all the business students stuck up like it seems or are there some nice ones? Not to be rude but I dont [sic] really care much about getting in there anyway and so I am not even sure why im $[$ sic $]$ here.

jill

The author and a research assistant, both blind to condition, rated participant responses for interpersonal helping along five dimensions which were based loosely on measuring the opposite behaviors as the original authors who used the task to measure interpersonal deviance. Instead of measuring hurtful, rude, or embarrassing remarks as done by Christian \& Ellis (2011), I measured each email response on the basis of five markers of helping behavior: 1) salutation and 2) signature; 3) language that reinforced a desire to help such as, "Hope this helps!" or “Great question!”; 4) inclusion of specific, helpful advice that addressed the question; and, 5) whether the tone of the email was helpful and friendly. Scores on each of these dimensions was summed, resulting in scores ranging from zero to five, with high scores indicating more helpful behavior. For example, a very helpful email response would contain several of these helping indicators (e.g., a salutation and signature which offers the possibility of future interactions, as well as concrete advice that answered the question at hand). An unhelpful email contained no salutation or signature, might have mocked the participant, and/or contained little advice that the participant could actually use.

The two coders rated all of the emails and achieved good reliability (Email 1: $\mathrm{ICC}_{2}=$ .874; Email 2: $\mathrm{ICC}_{2}=.921 ;$ Email 3: $\left.\mathrm{ICC}_{2}=.913\right)$ and absolute agreement (Email 1: $\mathrm{ICC}_{2}=$ .840 ; Email 2: $\mathrm{ICC}_{2}=.921 ;$ Email 3: $\left.\mathrm{ICC}_{2}=.914\right)$, and because the scores on the emails were 
significantly correlated (all $r$ 's $>.439, p<.01$ ), I created a composite variable by averaging the scores on the three emails for each participant across both raters $(\alpha=.92)$.

\section{Study 1b: Results}

Four participants had to be removed for failing to follow the directions and completing the email task first before participating in the loneliness manipulation presented online via Qualtrics. In the same manner as with Study 1a, another nine participants were removed for responding to the loneliness scale in such a way that their feedback was not believable (i.e., I removed six participants in the not-lonely condition who agreed to four or more items and three participants in the lonely condition who agreed to one or fewer items). In total, 13 participants (16\%) were removed from the sample. The results provided below are based on the remaining 66 participants (35 lonely, 31 not lonely).

Table 3 presents means, standard deviations and correlations between the Study $1 \mathrm{~b}$ variables. This study failed to find a significant relationship between loneliness and interpersonal helping $(\mathrm{r}=-.096, p>.05)$. Consistent with Study 1a, manipulating loneliness did correlated with the need to belong $(\mathrm{r}=-.072, p>.05)$. The need to belong was significantly correlated with attributions indicating that those with a high need to belong tend to hold more stable attributions about their current level of loneliness.

\section{Manipulation Check}

State Loneliness. Consistent with Study 1a, the effectiveness of the loneliness manipulation was assessed in two ways. First, as intended, participants in the lonely condition agreed to more items than those in the not-lonely condition $\left(\mathrm{M}_{\text {lonely }}=8.29 \mathrm{vs} . \mathrm{M}_{\text {not-lonely }}=.58\right.$, $F(1,64)=115.10, p<.000)$. Second, there were significant differences for each of these state emotions, with the exception of excluded-included. Participants in the lonely condition felt more 
lonely $\left(\mathrm{M}_{\text {Lonely }}=4.17, \mathrm{M}_{\text {Not-Lonely }}=3.77, F(64)=4.83, p<.05\right)$ and abandoned $\left(\mathrm{M}_{\text {Lonely }}=4.09\right.$, $\left.\mathrm{M}_{\text {Not-Lonely }}=3.74, F(64)=5.48, p<.05\right)$, as well as sadder $\left(\mathrm{M}_{\text {Lonely }}=4.40, \mathrm{M}_{\text {Not-Lonely }}=3.74\right.$, $F(64)=8.39, p<.01)$ and more depressed $\left(\mathrm{M}_{\text {Lonely }}=4.37, \mathrm{M}_{\text {Not-Lonely }}=3.65, F(64)=12.26, p<\right.$ .001). However, individuals did not feel any more excluded or included based on their loneliness feedback $\left(\mathrm{M}_{\text {Lonely }}=4.00, \mathrm{M}_{\text {Not-Lonely }}=3.77, F(64)=2.11, p>.05\right)$.

\section{Test of Hypotheses}

Hypothesis 1 proposes that state loneliness leads to increased helping behavior. I regressed helping on the loneliness condition, centered need to belong, centered attributions, and the interactions between the two. The results of this analysis can be seen in Table 4. In the first step I regressed helping on the loneliness condition and found no main effect of loneliness. In fact, the sign of the coefficient and correlation suggests that state-lonely people were less helpful $\left(\mathrm{M}_{\text {Lonely }}=2.66, \mathrm{M}_{\text {not-lonely }}=2.89 ; \mathrm{b}=-.12, t(65)=-.771, p=.44\right)$. Thus, $\mathrm{I}$ found no support for Hypothesis 1.

In the second step, I entered loneliness and the centered moderator variables of need to belong and attributions and found no significant main effects for either moderator. In the third step, I entered all two-way interactions and found a marginal interaction between loneliness and the need to belong $(b=.30, t(60)=1.85, p=.07)$; however, this interaction becomes nonsignificant once the three-way interaction is entered in the final step. Further, although the plotting of simple slopes reveals the hypothesized pattern of results (i.e., Figure 2a shows that lonely individuals with a high need to belong are more helpful than lonely participants with a low need to belong), there were no significant differences revealed through examination of the effect of simple slopes at the mean, nor at one standard deviation above or below the mean. Therefore, I did not find support for Hypothesis 2. 
There was, however, a significant interaction between loneliness and attributions $(b=-$ $.354, t(60)=-2.763, p<.01)$. As can be seen in Figure $2 \mathrm{~b}$, plotting the simple slopes reveals that when individuals believe their degree of loneliness is stable and unlikely to change (Hypothesis 3b), lonely people are less helpful than not-lonely people $(\mathrm{b}=-.474, \mathrm{SE}=.208, t=-.2275, p=$ .026). However, simple slopes analysis at the mean and one SD below the mean (i.e., when attributions are unstable) were not significant $(\mathrm{b}=.214, \mathrm{SE}=.215, t=.997, p=.322)$. To further characterize the nature of this interaction I used the Johnson-Neymann technique and the SPSS script provided by Hayes \& Matthes (Hayes \& Matthes, 2009; Johnson \& Neyman, 1936). The conditional effect of attributions on helping behavior transitioned to significance at an attribution score of $.7823, b=-.345, \mathrm{SE}=.17, t=-1.99, p=.05$. Thus, there is a significant difference in helping among lonely and not lonely when attributions are above .7823 (i.e., when attributions are stable). Supporting Hypothesis 3b, I found that people who feel lonely and make stable attributions are significantly less likely to help than their non-lonely counterparts. However, I did not find support for Hypothesis 3a: individuals experiencing loneliness who hold unstable attributions for this emotion were not more helpful than their non-lonely counterparts.

The three way interaction between loneliness, attributions and the need to belong was not significant $(b=-.065, t(59)=-.402, p=.689)$. However, I utilized planned contrasts to test the specific hypotheses that lonely people with a high need to belong and unstable attributions would be more helpful than their not-lonely counterparts (Hypothesis 4a) and that lonely participants with a low need to belong and stable attributions would be less helpful than their not-lonely counterparts (Hypothesis 4b).

To test Hypothesis 4a, I examined the conditional effects of loneliness on helping when the need to belong was one standard deviation above the mean (i.e., high need to belong) and 
attributions were one standard deviation below the mean (i.e., unstable). This compares the estimates 3.31 and 1.98 and while the interaction did not reach conventional levels of significance $(\mathrm{b}=.67, \mathrm{SE}=.35, t=1.93, p=.059)$, the results are in line with Hypothesis 4a such that lonely participants with a high need to belong and unstable attributions tended to be more helpful than their non-lonely counterparts.

To test Hypothesis 4b, I examined the conditional effects of loneliness on helping when the need to belong was one standard deviation below the mean (i.e., low need to belong) and attributions were one standard deviation above the mean (i.e., stable). This compares the points 3.5 and 2.04 again revealed an interaction that again did not reach conventional levels of significance $(\mathrm{b}=-.73, \mathrm{SE}=.42, t=-1.72, p=.09)$, although is indicative of a trend towards support for Hypothesis 4b. Specifically, lonely people with a low need to belong and stable attributions tended to be less helpful than their non-lonely counterparts.

To rule out task engagement as an explanatory factor consistent with Study 1a, following the email task participants were asked to reflect on their engagement in the task by responding to the same nine items $(\alpha=.96)$ used in Study 1a (Rich et al., 2010). While task engagement did significantly predict the helpfulness on the email task $(b=.448, t(64)=3.11, p=.003)$, loneliness did not significantly affect task engagement $(b=-.031, t(64)=-.243, p=.81)$. In addition, participants in the lonely condition were no more engaged in the email task than participants in the not-lonely condition $\left(\mathrm{M}_{\text {not-lonely }}=5.43, \mathrm{M}_{\text {lonely }}=5.37, F(1,64)=.059, p=\right.$ $.81)$, nor did they use more words in their email responses $\left(\mathrm{M}_{\text {not-lonely }}=76.16, \mathrm{M}_{\text {lonely }}=87.13\right.$, $F(1,64)=1.29, p=.26)$. 


\section{Study 1b: Discussion}

Study 1a revealed a main effect of loneliness on helping behavior and an interaction with the need to belong that were not replicated in Study 1b. However, I found strong evidence that the attributions lonely individuals make can impact helping behavior. Namely, when a lonely person makes stable attributions about their emotion, they are less likely to help. The results of probing the three-way interaction did not reach conventional levels of significance but were suggestive of a conditional effect of loneliness $\mathrm{x}$ attributions at different levels of the need to belong. Specifically, state-lonely people who had both a high need to belong and unstable attributions tended to be more likely to help than similar people who are not lonely, and when state-lonely people had a low need to belong and make stable attributions, they tended to be less likely to help than similar others who are not lonely. This experiment adds to what we know about the behavior of lonely people because it suggests that both motivation and ability are important, and shows the conditions under which lonely people might choose to help others.

One limitation of this study is that the modest sample size in the present study $(n=66)$ may have limited the statistical power and played a role in limiting the significance of some of the statistical comparisons conducted. To investigate this possibility I conducted a post hoc power analysis with the program $G^{*}$ Power (Faul, Erdfelder, Lang, \& Buchner, 2007) to determine whether I had enough power to detect the two-way and three-way interactions. This analysis revealed that the $\Delta \mathrm{R}^{2}(.13)$ for the two-way interactions yielded a calculated effect size of $f^{2}=.149$ and an achieved power of $\mathrm{d}=.72$. For this effect size an $\mathrm{n}$ of approximately 78 would have been needed to obtain statistical power at the recommended .80 level (Cohen, 1988). Given the extremely small $\Delta \mathrm{R}^{2}(.002)$ on the three-way interactions a significantly larger sample would have been necessary to find significant results at this effect size. 
Another limitation of Studies $1 \mathrm{a}$ and $1 \mathrm{~b}$ are the use of a student sample. Although both of these studies utilize a student population, the dependent measures of helping behavior might reasonably and frequently be expected among a working population. Study 1a measured helping by making suggestions to a cover letter. Workers are often asked to proofread materials written by a colleague. Study $1 \mathrm{~b}$ operationalized helping by coded responses to email messages, a behavior that most workers engage in every day. However, Study 2 addresses the limitation of the student sample by testing the model among a population of working adults. 


\section{CHAPTER 5: STUDY 2}

Study 2 utilizes an online sample from a national database of online workers. I utilized a measure of state loneliness to rule out the possibility that the results are an artifact of the manipulation used in both Experiments 1a and 1b. Study 2 also utilizes a different dependent variable to capture helping behavior in which helping comes at a personal cost to the participant.

\section{Study 2: Methods}

\section{Participants}

Participants were 65 members of the Amazon mTurk national database of online workers who were paid for their participation. Fifteen participants (23\%) failed attention checks and were removed before completing the study. The remaining 50 participants were on average 37.48 years old. Of these, 30 were female and 41 were non-Hispanic white. Participants were predominantly employed (39 participants) with an average of 17.76 years work experience.

\section{Procedure}

The study was conducted online via Qualtrics in exchange for pay. The average time spent on the study was 16.38 minutes, however four participants spent under nine minutes and one took over 35. Participants who spent either too little or too much time were likely not paying attention to the study or completed it with interruptions. Therefore, these five participants were removed from the sample. The results reported below are based on the remaining 45 participants.

Participants first responded to personality measures including measures of the need to belong and attributions, as well as measures of trait- and state-emotions. Participants then completed a test of verbal ability in which they had two minutes to solve up to 20 word 
association puzzles. Participants were told that as part of the study half of them would be randomly chosen to share any number of their correct answers with a future participant if they wanted to, and the other half would be randomly assigned to receive the number of correct answers chosen by a past participant. Participants learned that they would earn one entry into a $\$ 10$ lottery for every puzzle they ultimately answered correctly; thus, helping the "partner" by sharing correct answers diluted the participant's own chances in the lottery. In reality, all participants were told that they had randomly been chosen to share answers with a "partner."

The verbal ability task utilized 20 items from the Remote Associates Test developed by Mednick \& Mednick $(1962,1967)$ for their studies on creativity. In this task, participants are presented with three words and must come up with a fourth word that links the set together. For example, the answer to the puzzle containing the three words "paint, doll, and cat" is "house" as in house paint, dollhouse, and house cat. Participants saw two sample RAT puzzles and then had two minutes to complete 20 RAT puzzles (see Appendix A for the complete list of puzzles). Participants could leave puzzles blank if they did not know the answer. After two minutes, participants were given accurate feedback on the number of puzzles they solved correctly and were asked how many of those answers they would like to share with their partner, ranging from 0 if they did not want to share any answers, to the total number of puzzles they answered correctly. Finally, participants provided demographic information, were debriefed, and paid.

\section{Measures}

Unless otherwise indicated, items were measured with a five-point Likert-type scale ranging from 1 = "Strongly Disagree" to 5 = "Strongly Agree".

State-Loneliness. A state measure of loneliness $(\alpha=.950)$ was collected by adapting the UCLA Loneliness scale (Russell, 1996) to indicate how often participants felt a particular way 
during the past seven days on a scale of 1 to $5(1=$ never or 0 days; $5=$ always or 7 days $)$.

Consistent with the traditional UCLA Loneliness scale, half of the items were positively worded (e.g., "How often did you feel that you were in tune with the people around you?") and half were negatively worded (e.g., "How often did you feel alone"). Positively worded items were reverse coded and then averaged across all 20 items. High scores indicate higher levels of state loneliness.

Need to belong. The need to belong (Leary et al., 2013) was assessed with the same seven-item measure in Study $1 \mathrm{a}$ and $1 \mathrm{~b}(\alpha=.871)$. Higher values indicate a stronger need to belong.

Attributions. Attributions $(\alpha=.793)$ for loneliness were assessed with the same three items from the Revised Causal Dimension scale (McAuley et al., 1992) as in Study 1b. Again, responses to these three items were averaged and higher values indicate more stable attributions (i.e., permanent, stable over time, and unchangeable) while lower values indicate unstable attributions (i.e., temporary, variable over time, and changeable).

Interpersonal Helping. Scores on the RAT ranged from zero to 20, with a mean of 8.11 (s.d. $=3.97)$. The number of answers provided to a partner ranged from zero to 11 , with a mean of 4.11 (s.d. = 3.49). In order to create a dependent variable that equalized helping behavior across participants who ranged in verbal ability, a percentage of the number of solutions given and the total number of correct puzzles was created using the formula:

$$
\text { Helping }=1-([\# \text { puzzles correct }-\# \text { solutions given }] / \# \text { puzzles correct }) \text {. }
$$

This created a dependent variable that ranged from 0 to 1 , with greater numbers indicating increased helpfulness. Thus, if someone answered five puzzles correctly and offered all five responses to his/her partner, this person's helping score is 1. Likewise, if someone answered 20 
puzzles correctly and provided 10 answers to his/her partner, this person's helping score is .50 .

The average participant offered just over half his/her correct answers (mean $=.55$, s.d. $=.435$ ).

Control Variables. I controlled for a number of variables because of their connection to loneliness or interpersonal helping. First, Big 5 personality variables, assessed using Donnellan, Oswald, Baird \& Lucas (2006), have been linked to trait loneliness (Cacioppo et al., 2006;

Teppers et al., 2013), as well as with helping behavior (Organ \& Ryan, 1995). I also controlled for trait positive and negative affect, assessed using the PANAS-X (Watson, Clark, \& Tellegen, 1988), as well as for trait loneliness as measured with the single item "lonely" among the PANAS-X measure. Controlling for these trait emotions can help reduce the potential for common method effects (Podsakoff, MacKenzie, Lee, \& Podsakoff, 2003). Finally, I controlled for gender because research has shown that women are more likely to be helpful than are men (Farrell \& Finkelstein, 2007).

\section{Study 2: Results}

Table 5 provides the means, standard deviations, and correlations between the Study 2 variables. The correlations show that state loneliness is significantly related to Big 5 personality variables in expected ways. It is positively correlated with neuroticism $(\mathrm{r}=.629, p<.01)$ and negatively correlated with the other Big 5 variables. In addition, state loneliness is significantly correlated with trait-loneliness $(\mathrm{r}=.634, p<.01)$, depression $(\mathrm{r}=.719, p<.01)$ and negative affect $(\mathrm{r}=.460, p<.01)$. This suggests that those people who reported feeling lonely over the past week also generally feel more negative emotions and are generally lonely and depressed. Interestingly, the need to belong correlates negatively with state loneliness $(\mathrm{r}=-.433, p<.01)$ but not with trait loneliness $(\mathrm{r}=-0.142, p>.05)$. This is consistent with past researchers who have found that chronic loneliness and the need to belong are unrelated (Leary et al., 2013), and 
suggests that those with a high need to belong may be less apt to feel state loneliness. This could be because they are better able to pick on the social cues that help them make friends and keep loneliness at bay (Gardner et al., 2005; Pickett et al., 2004), or simply because they have fulfilled the higher level of social contact to fulfill their belonging needs and thus do not feel lonely. In addition, although not significant, state loneliness $(r=-.18)$ and trait loneliness $(r=-$ .20) correlate negatively with helping behavior suggesting individuals who are feeling loneliness either chronically or recently tend to be less helpful than their non-lonely counterparts.

\section{Collinearity}

Several of the variables in this study have medium to high correlations. In particular, state loneliness and depression correlate at .719. Following guidelines suggested by Tabachnick \& Fidell (2007), I omitted depression from my analyses because it likely contains redundant information that will inflate the error terms and weaken my analysis. To further test for collinearity problems, I followed guidelines set by Belsley, Kuh \& Welsch (1980), who suggest collinearity may be an issue when the condition index is greater than 30 for a given dimension coupled with variance proportions greater than .50 for at least two different variables. A high condition index is associated with variance inflation in the standard error resulting in parameter estimates that become uncertain. I first regressed helping on all of the controls and in the second step added state loneliness, the need to belong, and attributions. This initial screen revealed one dimension with a condition index close to 30 (29.54) and the Big 5 variables for openness (.75) and agreeableness (.53) had high variance proportions. I therefore deleted openness and reran the regression analysis. The remaining control variables passed the test for collinearity. 


\section{Test of Hypotheses}

Table 6 shows the results of the hierarchical regression analyses testing my hypotheses. In the first step, I entered the control variables, none of which significantly affected helping behavior. Hypothesis 1 proposed that state loneliness will be positively related to interpersonal helping. As shown in Table 6, when I entered loneliness in the second step of the hierarchical regression, it did not have a significant relationship with helping behavior $(b=-.07, p>.10)$. Thus, I did not find support for Hypothesis 1.

To test the significance of the need to belong and attributions as moderators, I entered the mean-centered variables in Step 3, all of the two-way interaction terms in Step 4, and the threeway interaction in Step 5. In Step 4, I found both the need to belong $(b=.20, t(30)=1.926, p=$ $.064)$ and attributions $(b=-.05, t(30)=-1.904, p=.067)$ to have interactions which led to a significant increase in the amount of variance explained $\left(\Delta \mathrm{R}^{2}=.20, \mathrm{~F} \Delta(30)=3.182, p=.038\right)$. The interactions between loneliness and the need to belong $(b=.24, \mathrm{SE}=.105, t(29)=2.318, p$ $=.028)$ and loneliness and attributions $(b=-.06, \mathrm{SE}=.027, t(29)=-2.138, p=.041)$ became significant in Step 5 with the addition of the three-way interaction, although the three-way interaction itself was not significant $(b=.04, t(29)=1.491, p=.147)$.

To test Hypothesis 2, I plotted the estimates of helping behavior at one standard deviation above and below the mean on the need to belong as suggested by Aiken and West (1991). As can be seen in Figure 4a, participants were less likely to help when they were in the lonely condition and had a low need to belong. Probing the interaction between loneliness and the need to belong reveals a pattern of results that is consistent with the results found in Study 1b, although here reaches significance. The unstandardized simple slope for participants one SD below the mean on the need to belong was significant $(b=-.249, \mathrm{SE}=1.08, t=-2.301, p=.027)$. 
Analysis at the mean and one SD above the mean are not significant. Thus, I found that lonely people with a low need to belong were significantly less helpful than their non-lonely counterparts. This provides support for Hypothesis 2.

To test Hypothesis 3a and 3b, I conducted a simple slope analysis of the interaction between loneliness and attributions. As can be seen in Figure $4 \mathrm{~b}$, the analysis of simple slopes reveal significant differences between state-lonely and non-lonely participants at both the mean $(b=-.22, \mathrm{SE}=.091, t=-2.45, p=.018)$ and at one $\mathrm{SD}$ below the mean (i.e., Hypothesis $3 \mathrm{a} ; b=-$ $.169, \mathrm{SE}=.084, t=-2.01, p=.05$ ) and at one SD above the mean (i.e., Hypothesis $3 \mathrm{~b} ; b=-.277$, $\mathrm{SE}=.124, t=-2.236, p=.03)$. Thus, I find strong support for both Hypothesis $3 \mathrm{a}$, in which state-lonely individuals who make unstable attributions are significantly more likely to help than non-lonely individuals with unstable attributions, and Hypothesis 3b, in which state-lonely individuals who believe their degree of loneliness is stable and unlikely to change are significantly less likely to help than non-lonely individuals who also make stable attributions, suggesting attributions are indeed an important moderator of the state-loneliness and helping behavior link.

The three-way interaction between loneliness, the need to belong, and attributions was not significant $(b=.04, t(29)=1.491, p=.147)$. However, I utilized planned contrasts to test Hypotheses $4 \mathrm{a}$ and $4 \mathrm{~b}$. Hypothesis $4 \mathrm{a}$ predicted that among those with unstable attributions, lonely people with a high need to belong would be more helpful than non-lonely people with a high need to belong. As shown in Figure 5, lonely people with a high need to belong who made unstable attributions were indeed more helpful than non-lonely individuals with the same characteristics. However, analysis of the conditional effect of loneliness on helping when the need to belong was one standard deviation above the mean (i.e., high need to belong) and 
attributions were one standard deviation below the mean (i.e., unstable) was not significant ( $b=$ $.28, \mathrm{SE}=.2, t=1.39, p=.18)$. Thus, Hypothesis $4 \mathrm{a}$ is not supported.

Hypothesis $4 \mathrm{~b}$ predicted that among those with stable attributions, lonely people with a low need to belong would be less helpful than not-lonely people with a low need to belong. Analysis of the conditional effects of loneliness on helping when the need to belong is one standard deviation below the mean (i.e., low need to belong) and attributions are one standard deviation above the mean (i.e., stable) was significant $(\mathrm{b}=-.57, \mathrm{SE}=.19, t=-2.93, p=.007)$. As shown in Figure 5, lonely people who make stable attributions and have a low need to belong are significantly less helpful than their non-lonely counterparts. Thus, I find support for Hypothesis $4 b$.

Finally, I conducted a mediation analysis to once again rule out task engagement as an explanatory factor for the link between state-loneliness and helping behavior. I used a three item measure to assess task engagement $(\alpha=.825)$ including the items, "I exerted my full effort on this task," "I devoted a lot of energy to this task," and "I tried my hardest to perform well on this task." State-loneliness did not predict task engagement $(b=-.2538, t(35)=-1.49, p>.05)$, and task engagement did not predict interpersonal helping $(b=.072, t(35)=.48, p>.05)$. I also added task engagement as a control variable in Step 1 of the regression analyses and it did not materially alter the results in subsequent steps.

\section{Study 2: Discussion}

There are two important limitations with Study 2. First, this study also suffers from a limited sample size that threatens the ability to find statistically significant results given the number of predictors in the model. A post hoc power analysis was conducted using the program $G^{*}$ Power (Faul et al., 2007) and a sample size of 45 . The addition of the two-way interactions in 
the regression equation yielded a $\Delta \mathrm{R}^{2}$ of $.201(\Delta \mathrm{F}(3,30)=3.18, p=.038)$. This equates to a calculated effect size of $\mathrm{f}^{2}=.25$ (between a medium and large effect size according to Cohen (1988)). Using an alpha level of $p<.05$ and testing the three two-way interactions and a total of 15 predictors yielded power of .76. A sample size of 49 would have been needed to reach the recommended power level of .80. Further post-hoc power analyses on the three-way interaction revealed that the non-significant results may also have been a result of a lack of statistical power. The addition of the three-way interaction in the regression equation yielded a $\Delta \mathrm{R}^{2}$ of $.045(\Delta \mathrm{F}(1$, $29)=2.22, p=.147$ ) or a calculated effect size of $\mathrm{f}^{2}=.047$ (a small effect size given Cohen's (1988) parameters) and achieved power of .29. The sample size would have needed to be 169 in order to reach conventional power levels of .80 .

Second, this study utilizes a ratio (the number of answers shared/the number of correct answers) as the primary dependent variable. This was done to adjust the actual helping behavior (i.e., the number of shared answers) for the effect of ability or the total number correct that could have been shared. However, some researchers have cautioned against using ratios as dependent variables (see Kronmal, 1993 for a review) which could lead to incorrect or misleading inferences about the effects of the independent variables on the dependent variable. One way to correct for this is to eliminate the ratio by using the numerator as the dependent variable and adding the denominator as a predictor. In this way, the coefficient measures the effect of loneliness on the number of shared answers after adjusting for the number correct. I reran these analyses using this approach and although the pattern of the results was the same, the significance of some of the statistical tests changed. I continued to find support for Hypothesis 2 and the interaction between the need to belong and state-loneliness $(b=1.887, t(3,29)=1.89, p=$ .037). In addition, the omnibus test of the three-way interaction between loneliness, the need to 
belong, and attributions was now significant $(\mathrm{b}=.475, \mathrm{t}(1,28)=2.071, \mathrm{p}=.048)$. Probing this interaction revealed support only for Hypothesis $4 \mathrm{~b}$ in which individuals with a low need to belong and stable attributions were less helpful $(b=-4.62, \mathrm{t}=-2.74, \mathrm{p}=.01)$. However, I did not find support for Hypothesis $3 \mathrm{a}$ or $3 \mathrm{~b}$ (the omnibus test of the interaction between loneliness and attributions was non-significant and probing of simple slopes revealed no significant differences across stable or unstable attributions). One other way to analyze this data would be to create interaction terms with the variables of interest and the number of correct puzzles (i.e., multiply every predictor variable by the number of correct puzzles to create new two-, three- and a fourway interaction). Given the limited sample size and the number of predictors, this analysis is not possible with the data presented. However, this analysis should be considered for future work involving this particular task and dependent variable. 


\section{CHAPTER 6: GENERAL DISCUSSION}

Research on loneliness is gaining traction and interest among the popular press (e.g., Bernstein, 2013; Cacioppo \& Patrick, 2008), associations such as AARP (e.g., Wilson \& Moulton, 2010), institutions like the U.S. Army, as well as academic and professional journals (see the special issue of The Journal of Psychology edited by Ami Rokach (2012)). This research has advanced and enlightened our understanding of the physical and psychological dangers associated with chronic loneliness. However, it does little to address the promise suggested by Gardner, Cacioppo and colleagues that loneliness might hold the key to prompt awareness of deficient social connections and motivate behavior to facilitate reconnection (Cacioppo et al., 2014; Pickett \& Gardner, 2005). My paper addresses this gap by showing how state feelings of loneliness, when combined with the need to belong and unstable attributions, can spur interpersonal helping behavior.

The results presented across three studies are summarized in Table 7 and offer support for the central research questions addressed which was how state loneliness impacts helping behavior, and who is most and least able to capitalize on the emotion to reconnect with others. My work looks at these effects both when the recipient of the helping behavior was a member of the same in-group (Study 1a and 1b) as well as a stranger (Study 2), and when helping came at a cost to the participant (Study 2). Although I did not find consistent support for a main effect of state loneliness leading directly to helping behavior (Hypothesis 1), I did find some support for the conditions under which state-loneliness impacted helping behavior. Namely, Hypothesis $3 \mathrm{~b}$ was supported across two studies and found that when individuals make stable attributions for 
their state-loneliness they are less likely to reach out to others to help. I also found mixed support for Hypothesis $4 \mathrm{~b}$ which described the deleterious effect of feeling lonely and having a low need to belong and stable attributions on helping behavior.

I found less consistent support for loneliness having a true social function. I only found a positive main effect in Study 1a the results of Studies $1 \mathrm{~b}$ and 2 are inconclusive for the positive effect of either unstable attributions or a high need to belong. In Study 1b, holding unstable attributions did not lead to increased helpfulness, but when combined with a high need to belong the results were trending towards increased helpfulness. While in Study 2, I found that holding unstable attributions led to more helpfulness, but did not find the positive, multiplicative effect of having a high need to belong and unstable attributions. Although theory predicts that state feelings of loneliness should drive people to initiate behavior that will ingratiate them back into the group (Gardner et al., 2000; Gardner et al., 2005; Pickett \& Gardner, 2005; Pickett et al., 2004), my studies do not reveal clear evidence supporting this. Further work is needed to understand the social function of loneliness.

While not central to my research questions, an interesting result that appeared in both Study $1 \mathrm{~b}$ and Study 2 is the increased helpfulness of not-lonely (i.e., well-connected) people with a low need to belong. More exploration is needed to account for this finding. It could be that other emotions are at play with this group. Perhaps the well-connected participant with a low need to belong does not want to be in the group, but knows that he or she should care about group membership. It could be these participants are motivated to help out of feelings of guilt that they should want to be more involved, or perhaps they help simply to confirm their selfimage and appearance as someone who is helpful. Helping behavior in these instances might be motivated by image or self-esteem maintenance rather than emotions (Crocker \& Wolfe, 2001). 


\section{Theoretical Implications}

My results extend our knowledge on loneliness in a number of important ways. First, I extend the behavior outcomes of loneliness to include prosocial, interpersonal helping, an important outcome variable for managers and organizations. To my knowledge, past research on the outcomes of loneliness at work is limited to only one study that found a negative relationship between loneliness and three different performance outcomes (Ozcelik \& Barsade, 2011). My work takes a different approach by exploring the social function of state loneliness and finds a positive outcome for loneliness, when combined with the need to belong and unstable attributions.

These findings are consistent with past researchers who have found that sad people help the most when they believe their mood is labile and can be changed (Manucia, Baumann, \& Cialdini, 1984). Others have found that people are helpful when the cost is low (Weyant, 1978) and when helping is intrinsically rewarding (R. F. Weiss, Boyer, Lombardo, \& Stich, 1973). It appears that the same may apply to loneliness. State-lonely people are more helpful when they believe their mood can change, and perceptions of unstable attributions may relate to perceived costs of helping. If one believes it is possible to change one's loneliness, the behavior should be less costly than if the person believes the emotion has stable causes.

Second, my work adds to the discussion on the difference between state and trait emotions. It may be that when individuals make stable attributions for state emotions, their behavior manifests as if the emotion was a trait. This is consistent with prior work which has found that chronically lonely individuals are viewed as less attractive social partners (Lau \& Gruen, 1992; Rotenberg \& Kmill, 1992) and have problems initiating and maintaining social contact (Horowitz et al., 1982). Thus, even though individuals may only be feeling transient 
feelings of loneliness, if they believe the emotion is due to stable causes, according to my research they will be less likely to reach out to others to help—a behavior that might in fact alleviate their loneliness.

Third, I extend theories on belonging (Baumeister \& Leary, 1995) and belonging regulation (Gardner et al., 2000; Gardner et al., 2005; Pickett \& Gardner, 2005; Pickett et al., 2004) by considering when belonging needs can be most readily acted upon. The need to belong is a fundamental human need (Baumeister \& Leary, 1995; Maslow, 1943; Ryan \& Deci, 2000), but my work shows how it manifests in different behavior among different types of people. Lonely people with a low need to belong and stable attributions appear to be particularly susceptible to slipping into chronic loneliness because they are much less likely to reach out to others to help. Further, I extend the theory of belonging regulation by suggesting that the regulatory system proposed by the theory is subject to various contingencies that may disrupt its proper functioning. Namely, individuals may only be able to act upon the heightened awareness of deficient belonging goals if they are able to make unstable attributions for their loneliness.

Fourth, I utilize Vroom's (1964) ability-motivation interaction hypothesis to provide an account of why the impact of loneliness on helping behavior is inspired by both one's motivation to belong to the group as well as one's perceived ability to change one's loneliness. While empirical tests confirming the interactive effects of ability and motivation are not new, as applied to loneliness, I have expanded our knowledge of when loneliness is most and least likely to lead to helping behavior. The need to belong and attributions seem to work together to both amplify (in the case of lonely individuals with a high need to belong and unstable attributions) and attenuate (when lonely individuals have a low need to belong and make stable attributions) the impact of loneliness on helping. 


\section{Managerial Implications}

While helping behavior has been shown to be a valuable and necessary behavior for effective organizational functioning (e.g, Borman \& Motowidlo, 1997; George \& Brief, 1992), I am certainly not suggesting that managers or organizations purposely make their employees feel lonely in order to increase helping behavior. In fact, evidence of a direct connection between loneliness and helping was weak and trending negative in two of the three studies. Instead, I encourage managers to understand the work conditions that might induce interpersonal and/or collective isolation (e.g., work-at-home, virtual teams, extended travel, constant connection via technology), and realize that unless they also foster conditions that encourage reciprocity, team cohesion and affective commitment, as well as encourage employees' beliefs in their ability to reconnect with others, managers might find their employees spiraling into a situation in which state loneliness becomes chronic and a drain on the team's social capital and performance.

I am also not suggesting that managers seek to hire only employees with a high need to belong. Although those with a high need to belong are critically important because they may be more likely to contribute to the betterment of the group, maintain open communication, and build connections across teams (Cacioppo et al., 2014), organizations presumably need individuals who are both high and low on the need to belong. Those with a low need to belong may be more likely to be sales representatives, visionaries, leaders in R\&D, or others who feel free to explore new ideas and territories on their own, and are not concerned with impressions of the group when raising new ideas or strategies.

However, when it comes to the attributions one makes for loneliness, organizations do want to encourage employees to hold unstable attributions such that they believe they can do something to actively manage their emotions. For those employees who hold stable attributions 
about their feelings of loneliness, an intervention to address this maladaptive social cognition might be effective. A meta-analysis of 50 studies of interventions to reduce loneliness found that compared to programs intended to improve social skills, enhance social support, or increase opportunities for social interaction, the most successful interventions were those that addressed deficits in social cognition (Masi, Chen, Hawkley, \& Cacioppo, 2011) such as reframing perceptions of loneliness (Conoley \& Garber, 1985) or decreasing thought distortion through problem solving coping skills (Williams et al., 2004).

Managers might also look to foster norms of reciprocity by recognizing and rewarding helping behavior among team members. They should work to encourage friendships within and outside of work that can build psychological safety and create a culture of team cohesion. Organizations should also be aware that inspiring a sense of connection to a larger purpose through shared commitment to values that resonate with employees will go a long way to promoting a sense of connection to the organization that could combat feelings of loneliness among employees. This connection between the individual, team, and organization may be the key for managers looking to capitalize on the social function of loneliness.

\section{Limitations and Directions for Future Research}

Several limitations with the experiments reported here are worth noting. First, although I make large strides in understanding when loneliness is related to helping behavior, my work does not explain why this might be so. Explanations for the psychological mechanism linking loneliness to helping should be explored. Norms of reciprocity, team cohesion, and affective commitment have already been suggested, but there are other models that connect negative emotions to prosocial behavior which could be considered. The negative-state relief model posits that negative moods are accompanied by a corresponding need to reduce the bad feelings, 
and that this drive may be fulfilled by any mood-elevating behavior, including helping (Baumann et al., 1981; Cialdini \& Kenrick, 1976). However, the design did not allow for testing loneliness after the helping behavior to know if it was in fact used to improve feelings of connectedness, or provide an alternative mood boost (such as praise) before helping such as in the experiments on the negative-state relief model by Cialdini and colleagues (e.g., Cialdini, Darby, \& Vincent, 1973a).

Second, Study 2 uses nonexperimental data so it is impossible to know if the presumed effect of state loneliness on helping is a real causal effect, or merely a correlate of the causal effect, or even part of a larger set of factors that cause helping behavior. This limitation is addressed with the experimental design of Studies $1 \mathrm{a}$ and $1 \mathrm{~b}$ which provide evidence for the causal effect in which manipulating feelings of state loneliness led to increased helping behavior among those induced to feel more lonely. To more fully explore the causal nature within a work environment, future research could utilize longitudinal designs among employees within one organization with both self- and other-reported helping behavior to determine: a) the job and work design factors that lead to state loneliness, and b) how feelings of state loneliness at one time impact helping behavior and emotions at a subsequent time.

Third, is difficult to predict the effect size and power necessary to detect significant effects when the work is novel and there is no basis on which to judge power. As already discussed, Study $1 \mathrm{~b}$ and 2 were underpowered yet still found some significant effects. Future studies should consider larger sample sizes to detect the two- and three-way interactions suggested by this work.

This dissertation has led to a number of interesting ideas for future study. First, although there is a common core experience of loneliness, does loneliness in one domain (i.e., emotional 
loneliness or lacking a bond with a significant other) impact feelings of loneliness in another (i.e., social loneliness or lacking a rich social network of friends or colleagues)? One study by Russell and colleagues found that the coping mechanisms chosen differed by the type of loneliness felt, with those experiencing emotional loneliness reporting they were more likely to engage in behaviors that enabled them to form new relationships, whereas the socially lonely did not (Russell, Cutrona, Rose, \& Yurko, 1984). This suggests that those feeling lonely at work (i.e., experiencing social loneliness) might be more likely to utilize helping behavior while those experiencing emotional loneliness would not. However, this study utilized a self-report of coping techniques rather than a behavioral measure and operationalized social and emotional loneliness with single item measures. Future work could explore whether whether satisfying social connections at work can make up for deficient personal connections and whether a deeply satisfying emotional connection at home can make up for a dearth of colleagues at work, and how might loneliness in each of these domains impacts behavior.

Future research could also explore the antecedents and outcomes of feelings of state loneliness within an organization. I speculate that factors such as working at home and virtual teams might be related, primarily because of their impact on an employee's ability to form rich personal friendships at work. However, work-based antecedents could be studied to determine the extent to which job or role design (e.g., work-at-home, individual vs. collective goals), interpersonal factors (e.g., having a friend at work, norms of reciprocity), team-based factors (e.g., team cohesion) and organizational factors (e.g., affective commitment, shared vision) impact feelings of loneliness via relational and collective isolation at work. 


\section{Conclusion}

There are competing theories about the behavioral consequences of feeling lonely. Some suggest that loneliness is a "driving force" that motivates people to initiate social interactions (Sullivan, 1953; R. S. Weiss, 1973). However, others contend that feeling lonely decreases motivation for social connections as it heightens feelings of threat and suspicion and creates a sense of "paralyzing hopelessness and unalterable futility" (Fromm-Reichman, 1959). This paper provides an important first step in explicating the social function of loneliness and resolving these seemingly incompatible motivational accounts.

State loneliness among those with a low need to belong and/or stable attributions has the potential to persist to chronic levels. However, individuals who feel lonely and are able to understand the causes of the emotion as something under their power to control and/or who have a strong desire to belong to a group may be able to capitalize on the social function of the emotion. My work is among the first to show a positive behavioral outcome of loneliness, and I hope to raise awareness among managers and organizations that they can counteract social and environmental factors which could be causing their workers to feel lonely. I urge managers to understand the potential for loneliness that exists within their organization and alert them that if loneliness is allowed to persist to chronic levels it will have deleterious effects on their employees' health and productivity. However, if managers can create opportunities for friendships, norms of reciprocity, group cohesion, and affective commitment, they hold the key to capitalizing on the social function of loneliness. 
Table 1: Means, standard deviations, and correlations among Study 1a variables ${ }^{\text {a }}$

\begin{tabular}{lllccc}
\hline Variable & Mean & s.d. & $\mathbf{1}$ & $\mathbf{2}$ & $\mathbf{3}$ \\
\hline 1. Loneliness $^{\mathrm{b}}$ & 0.04 & 1.01 & -- & & \\
2. Need to belong $^{\text {N. Task engagement }}$ & 4.94 & 1.04 & 0.11 & -- & \\
4. Number Suggestions $^{c}$ & 5.14 & 1.42 & 0.03 & 0.10 & -- \\
\hline
\end{tabular}

${ }^{\mathrm{a}} \mathrm{n}=73$ (35 not-lonely, 38 lonely)

${ }^{\mathrm{b}}$ Loneliness was coded $-1=$ not-lonely or $1=$ lonely

${ }^{c}$ Average number suggestions averaged across Rater 1 and 2

*. Correlation is significant at the 0.05 level (2-tailed).

**. Correlation is significant at the 0.01 level (2-tailed). 
Table 2. Study 1a: OLS regressions to predict number of suggestions

\begin{tabular}{lcc}
\hline Measures & \multicolumn{2}{c}{ Number of Suggestions } \\
& $(1)$ & $(2)$ \\
\hline Constant & $4.602^{* * *}$ & $4.549^{* * *}$ \\
Loneliness & $0.696^{*}$ & $0.707^{* *}$ \\
Need to Belong & 0.414 & 0.331 \\
Lonely x Need to Belong & & $0.468^{\mathrm{t}}$ \\
$\quad \mathrm{R}^{2}$ & $0.126^{* *}$ & .167 \\
$\Delta \mathrm{R}^{2}$ & & $0.039^{\mathrm{t}}$ \\
\hline
\end{tabular}

Note: $\mathrm{n}=73$. For loneliness, high-loneliness condition was coded as 1 and low loneliness condition was coded as -1 . Need to belong was mean-centered before conducting analyses, and this mean-centered variable was used in computing the interaction terms between loneliness and the need to belong. Entries in the columns represent unstandardized regression coefficients.

$* * * \mathrm{p}<.001$

$* * \mathrm{p}<.01$

$* \mathrm{p}<.05$.

${ }^{\mathrm{t}} \mathrm{p}<.10$ 
Table 3: Means, standard deviations, and correlations among Study $1 \mathrm{~b}$ variables ${ }^{\text {a }}$

\begin{tabular}{llllll}
\hline Variable & Mean & s.d. & (1) & (2) & (3) \\
\hline 1. Loneliness $^{b}$ & 0.06 & 1.01 & -- & & \\
2. Need to belong $^{\text {3. Attributions }}$ & 5.00 & 0.94 & -0.072 & -- & \\
4. Interpersonal helping $^{c}$ & 4.81 & 1.25 & 0.177 & $.296^{*}$ & -- \\
\hline
\end{tabular}

${ }^{\mathrm{a}} \mathrm{n}=66$ (31 not-lonely, 35 lonely)

${ }^{\mathrm{b}}$ Loneliness was coded $-1=$ not-lonely or $1=$ lonely

${ }^{\mathrm{c}}$ Helping on the three emails averaged across Rater 1 and 2

*. Correlation is significant at the 0.05 level (2-tailed). 
Table 4. Study 1b: OLS regressions to predict helping behavior

\begin{tabular}{|c|c|c|c|c|}
\hline Measures & $(1)$ & $(2)$ & $(3)$ & $(4)$ \\
\hline (Constant) & $2.772 * * *$ & $2.774 * * *$ & $2.829 * * *$ & $2.831 * * *$ \\
\hline Loneliness & -0.115 & -0.149 & -0.128 & -0.107 \\
\hline Need to belong & & -0.071 & -0.018 & -0.022 \\
\hline Attributions & & 0.132 & 0.031 & 0.035 \\
\hline Loneliness $\mathrm{x}$ need to belong & & & $0.301^{\mathrm{t}}$ & 0.282 \\
\hline Loneliness $\mathrm{x}$ attributions & & & $-0.354 * *$ & $-0.346 * *$ \\
\hline Attributions $\mathrm{x}$ need to belong & & & 0.12 & 0.105 \\
\hline Loneliness $\mathrm{x}$ need to belong $\mathrm{x}$ attributions & & & & -0.065 \\
\hline $\mathrm{R}^{2}$ & 0.009 & 0.026 & 0.156 & 0.158 \\
\hline$\Delta \mathrm{R}^{2}$ & & 0.017 & $.13^{*}$ & 0.002 \\
\hline \multirow{2}{*}{\multicolumn{5}{|c|}{$\begin{array}{l}\text { Note. } \mathrm{n}=66 . \text { Loneliness was coded } 1 \text { and not lonely was coded }-1 \text {. Continuous independent } \\
\text { measures were mean-centered before conducting analyses, and these mean-centered variables } \\
\text { were used to compute the interaction terms between continuous and categorical predictors. } \\
\text { Entries in the columns represent unstandardized regression coefficients. }\end{array}$}} \\
\hline & & & & \\
\hline $\begin{array}{l}* * * \mathrm{p}<.001 \\
* * \mathrm{p}<.01 \\
* \mathrm{p}<.05 \\
\mathrm{t} p<.10\end{array}$ & & & & \\
\hline
\end{tabular}


Table 5. Means, standard deviations, and correlations among Study 2 variables

$\begin{array}{llllllll} & \text { Mean } & \text { s.d. } & (1) & (2) & (3) & (4) & (5) \\ \text { 1. State Loneliness } & 2.35 & 0.77 & 1 & & & & \\ \text { 2. Need to belong } & 4.23 & 1.06 & -.433^{* *} & 1 & & & \\ \text { 3. Attributions } & 3.88 & 0.95 & -.520^{* *} & 0.207 & 1 & & \\ \text { 4. Helping Percent } & 0.55 & 0.44 & -0.183 & 0.003 & -0.034 & 1 & \\ \text { Controls } & & & & & & & \\ \text { 5. Extraversion } & 2.61 & 0.99 & -.416^{* *} & .332^{*} & 0.195 & 0.117 & 1 \\ \text { 6. Agreeableness } & 3.77 & 0.79 & -.470^{* *} & .608^{* *} & 0.248 & 0.194 & .323^{*} \\ \text { 7. Conscientiousness } & 3.72 & 0.89 & -.448^{* *} & 0.044 & 0.241 & 0.117 & 0.225 \\ \text { 8. Openness } & 3.96 & 0.82 & -.464^{* *} & .323^{*} & .565 * * & 0.045 & .369^{*} \\ \text { 9. Neuroticism } & 2.44 & 0.81 & .629^{* *} & -0.191 & -.381^{* *} & -0.109 & -.398^{* *} \\ \text { 10. Trait-loneliness } & 1.58 & 0.81 & .634^{* *} & -0.142 & -.478^{* *} & -0.201 & -.424 * * \\ \text { 11. Depression } & 2.26 & 0.82 & .719 * * & -.308^{*} & -.455^{* *} & -0.202 & -.323^{*} \\ \text { 12. Positive affect } & 3.37 & 0.67 & -.594 * * & .486^{* *} & .350^{*} & 0.046 & .398^{* *} \\ \text { 13. Negative affect } & 1.42 & 0.45 & .460^{* *} & -0.038 & -0.215 & 0.005 & -.440^{* *} \\ \text { 14. Gender } & 0.58 & 0.50 & -0.209 & 0.203 & 0.195 & 0.181 & 0.035\end{array}$
6. Agreeableness
(6)
(7)
(8)
(9)
(10)
(11)
(12)
(13)
7. Conscientiousness
$0.183 \quad 1$
8. Openness
$\begin{array}{lll}.532 * * & 0.031 \quad 1\end{array}$
9. Neuroticism
$\begin{array}{llll}-0.275 & -.701 * * & -0.187 & 1\end{array}$
10. Trait-loneliness
$\begin{array}{lllll}-.376 * & -.444 * * & -.389 * * & .440 * * & 1\end{array}$
11. Depression
$\begin{array}{lllllll}-0.274 & -.491 * * & -0.142 & .596 * * & .675^{* *} & 1\end{array}$
12. Positive affect
$\begin{array}{lllllll}.587 * * & .456 * * & .484 * * & -.441 * * & -.426 * * & -.415 * * & 1\end{array}$
13. Negative affect
$-0.126-.526 * *$
$-0.149$
$.678 * *$
$.477 * *$
$.605 * * \quad-0.279$
$.490 * * \quad 0.006$
0.259
0.081
$-.338$
0.038
0.246
0.155 
Table 6. Study 2: OLS regression results for the effect of loneliness, the need to belong, and attributions on helping behavior

\begin{tabular}{|c|c|c|c|c|c|}
\hline Variable & 1 & 2 & 3 & 4 & 5 \\
\hline \multicolumn{6}{|l|}{ Control } \\
\hline Extraversion & 0.05 & 0.05 & 0.05 & 0.01 & -0.02 \\
\hline Agreeableness & 0.10 & 0.09 & 0.13 & 0.16 & $0.23 \mathrm{t}$ \\
\hline Conscientiousness & 0.06 & 0.07 & 0.04 & 0.06 & 0.07 \\
\hline Neuroticism & -0.06 & -0.03 & -0.06 & -0.05 & -0.01 \\
\hline Trait Loneliness & -0.09 & -0.06 & -0.08 & -0.14 & -0.13 \\
\hline Positive Affect & -0.15 & -0.18 & -0.14 & -0.16 & -0.12 \\
\hline Negative Affect & 0.21 & 0.21 & 0.27 & 0.19 & 0.15 \\
\hline Gender & 0.06 & 0.06 & 0.05 & 0.00 & -0.03 \\
\hline \multicolumn{6}{|l|}{ Main } \\
\hline Loneliness & & -0.07 & -0.14 & -0.08 & -0.03 \\
\hline \multicolumn{6}{|l|}{ Moderators } \\
\hline Need to Belong & & & -0.08 & -0.10 & -0.07 \\
\hline Attributions & & & -0.03 & -0.01 & 0.01 \\
\hline \multicolumn{6}{|l|}{ Interactions } \\
\hline Lonely $\mathrm{x}$ need to belong & & & & $0.20^{\mathrm{t}}$ & $0.24 *$ \\
\hline Lonely $\mathrm{x}$ attributions & & & & $-0.05^{\mathrm{t}}$ & $-0.06^{*}$ \\
\hline Need to belong $\mathrm{x}$ attributions & & & & 0.01 & -0.02 \\
\hline Lonely $\mathrm{x}$ need to belong $\mathrm{x}$ attributions & & & & & 0.04 \\
\hline $\mathrm{R}^{2}$ & 0.11 & 0.12 & 0.17 & 0.37 & 0.41 \\
\hline$\Delta \mathrm{R}^{2}$ & & 0.01 & 0.05 & $0.20 *$ & 0.05 \\
\hline
\end{tabular}


Table 7. Comparison of results across experiments

\begin{tabular}{llll}
\hline Hypotheses & Study 1a & Study 1b & Study 2 \\
\hline H1: Loneliness --> Helping & Supported & Not Supported & Not Supported \\
& $p=.009$ & $p=.444$ & $p=.618$ \\
& Marginal & Not Supported & Supported \\
H2: Need to belong as moderator & $p=.077$ & $p=.103$ & $p=.028$ \\
& & Not Supported & Supported \\
& & $p=.322$ & $p=.030$ \\
H3a: Unstable attributions $\rightarrow$ more helping & Not tested & Supported & Supported \\
& & $p=.026$ & $p=.050$ \\
H3b: Stable attributions $\rightarrow$ less helping & Not tested & Marginal & Not Supported \\
H4a: Lonely/HNTB/Unstable $\rightarrow$ more & & $p=.059$ & $p=.176$ \\
helping & Not tested & Marginal & Supported \\
& & $p=.091$ & $p=.007$ \\
H4b: Lonely/LNTB/Stable $\rightarrow$ less helping & Not tested & &
\end{tabular}


Figure 1. Study 1a: Number of suggestions as a function of loneliness and the need to belong.

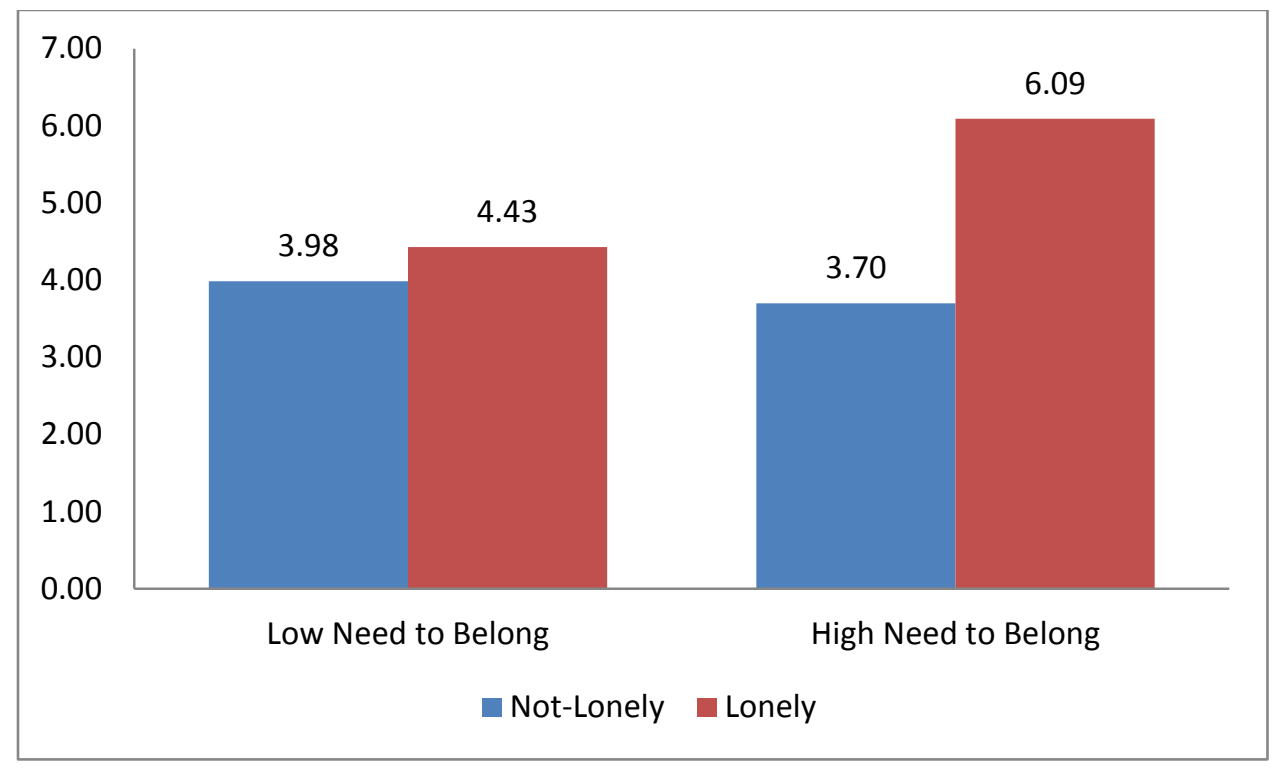

Note. For loneliness, the lonely condition was coded as 1 and not-lonely was coded as -1 . High levels of the need to belong are computed as one standard deviation above the mean, and low levels are computed as one standard deviation below the mean. 
Figure 2. Study 1b: Two-way interactions between loneliness and the need to belong and attributions

$$
\begin{aligned}
& \text { Not Lonely } \\
& \text { Lonely }
\end{aligned}
$$

Fig. 2a. Helping behavior as a function of loneliness and the need to belong

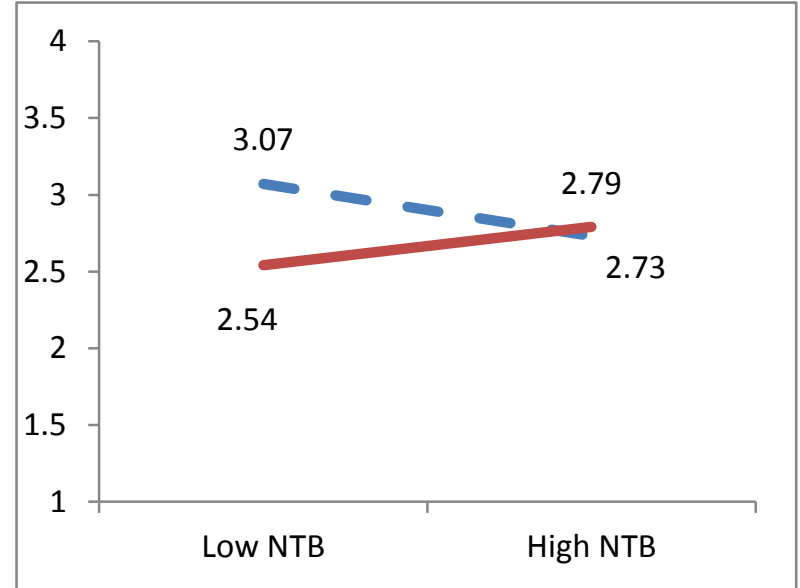

Fig. 2b. Helping behavior as a function of loneliness and attributions

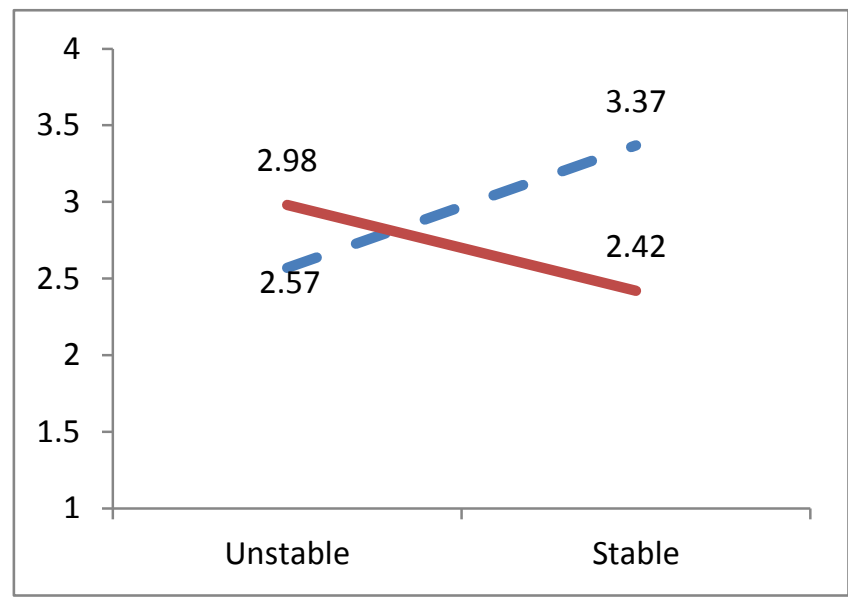

Note. Loneliness was coded 1 and not lonely was coded -1 . High levels of continuous variables are computed as one standard deviation above the mean, and low levels are computed as one standard deviation below the mean. 
Figure 3. Study 1b: Helping as a function of loneliness, the need to belong, and attributions

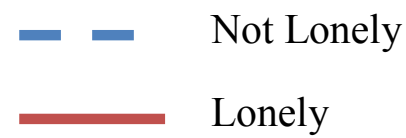

Fig. 3a. Helping behavior as a function of loneliness, the need to belong, and unstable attributions

$\underline{\text { Unstable Attributions }}$

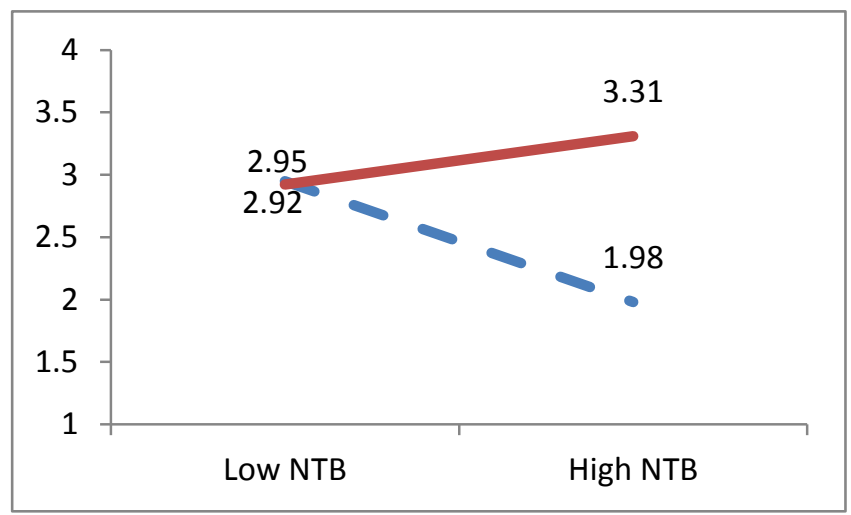

Fig. 3b. Helping behavior as a function of loneliness, the need to belong, and stable attributions

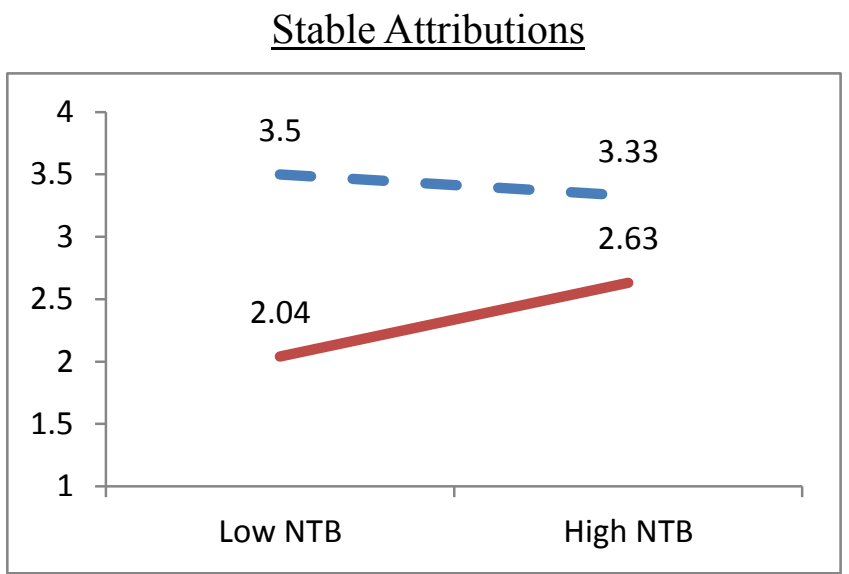

Note. Loneliness was coded 1 and not lonely was coded -1 . High levels of continuous variables are computed as one standard deviation above the mean, and low levels are computed as one standard deviation below the mean. 
Figure 4. Study 2. Two-way interactions between loneliness and the need to belong and attributions

- $-\quad$ Low State Loneliness

High State Loneliness

Fig. 4a. Helping percent as a function of loneliness and the need to belong

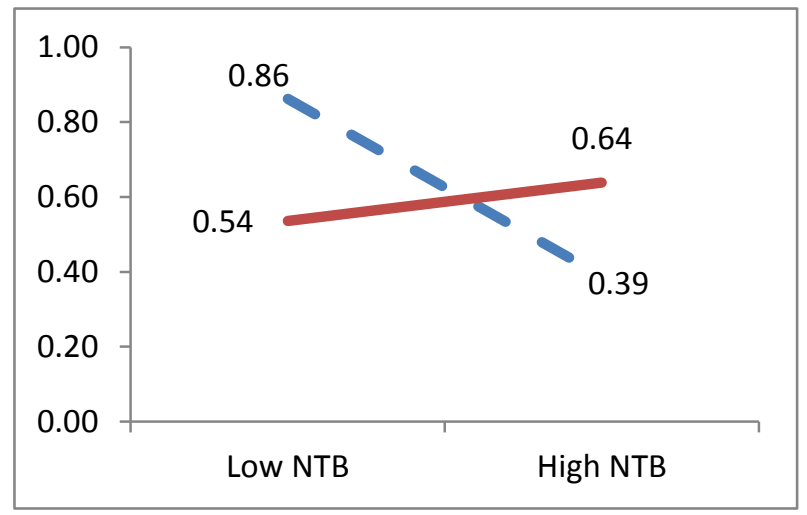

Fig. 4b. Helping percent as a function of loneliness and attributions

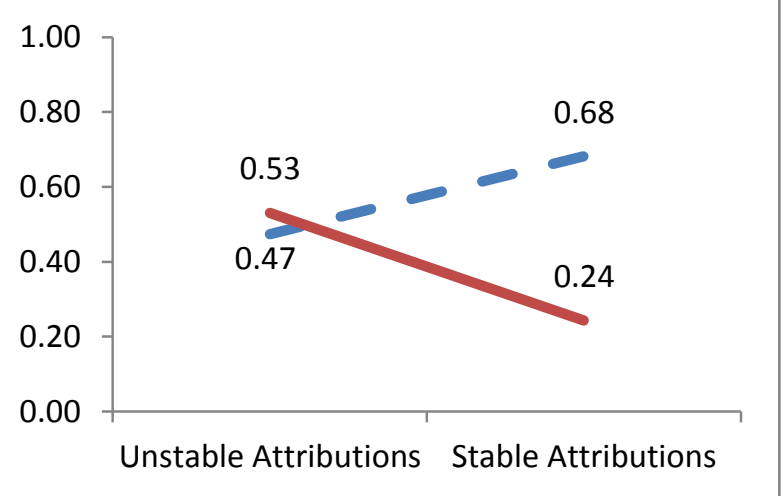

Note. High levels of continuous variables are computed as one standard deviation above the mean, and low levels are computed as one standard deviation below the mean. 
Figure. 5. Study 2: Helping as a function of loneliness, the need to belong and attributions

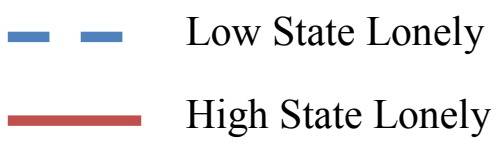

Unstable Attributions

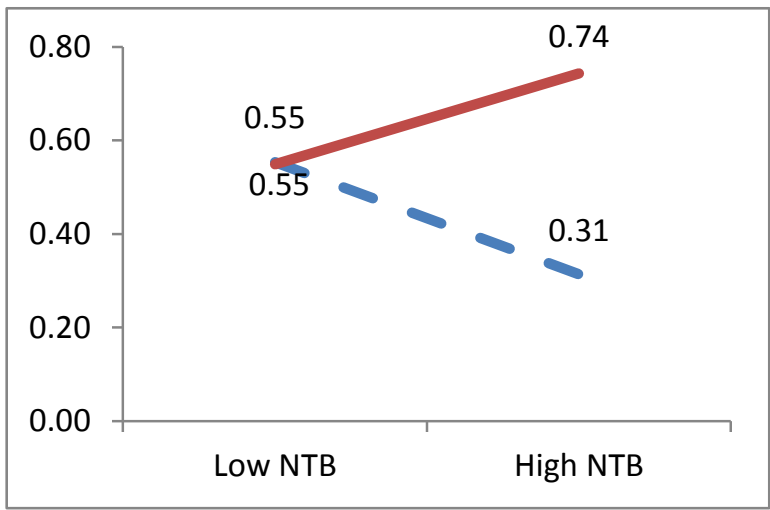

Stable Attributions

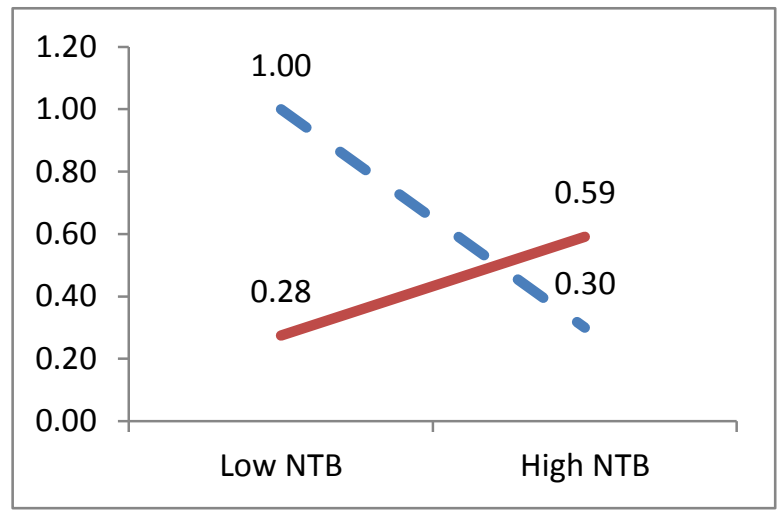

Note. High levels of continuous variables are computed as one standard deviation above the mean, and low levels are computed as one standard deviation below the mean. 


\section{APPENDIX: STUDY 2 RAT PUZZLES}

The following table presents items, solutions, and difficulty levels for the 20 RAT items used in Study 2. Some items were taken from Form 1 of the original RAT, devised by Mednick \& Mednick $(1962,1967)$ for their studies of creativity. Additional items were taken or modified from a set prepared by the late Kenneth S. Bowers and his colleagues (1990) for use in their studies of intuition. Solution norms were collected by Victor Shamas (1994). RAT items are listed in ascending order of difficulty, with the easier items at the top and harder items at the bottom.

\begin{tabular}{|c|c|c|c|}
\hline \multirow[b]{2}{*}{ Triad } & \multirow[b]{2}{*}{ Solution } & \multicolumn{2}{|c|}{ Difficulty } \\
\hline & & p(unsolved) & Normalized \\
\hline Falling Actor Dust & $\mathrm{STAR}^{3}$ & .15 & -2.38 \\
\hline Broken Clear Eye & GLASS $^{2}$ & .20 & -2.06 \\
\hline Widow Bite Monkey & SPIDER $^{1}$ & .25 & -1.75 \\
\hline Coin Quick Spoon & SILVER $^{2}$ & .30 & -1.44 \\
\hline Cracker Union Rabbit & $\mathrm{JACK}^{2}$ & .35 & -1.13 \\
\hline Manners Round Tennis & TABLE $^{2}$ & .40 & -0.81 \\
\hline Playing Credit Report & CARD $^{2}$ & .40 & -0.81 \\
\hline High Book Sour & $\mathrm{NOTE}^{2}$ & .45 & -0.50 \\
\hline Surprise Wrap Care & $\mathrm{GIFT}^{2}$ & .45 & -0.50 \\
\hline Barrel Root Belly & BEER $^{2}$ & .50 & -0.19 \\
\hline Speak Money Street & EASY $^{2}$ & .55 & +0.13 \\
\hline Envy Golf Beans & GREEN $^{1}$ & .60 & +0.44 \\
\hline Thread Pine Pain & NEEDLE $^{2}$ & .65 & +0.75 \\
\hline Inch Deal Peg & SQUARE $^{1}$ & .70 & +1.06 \\
\hline Magic Plush Floor & CARPET $^{2}$ & .70 & +1.06 \\
\hline Bump Throat Sum & LUMP $^{2}$ & .75 & +1.34 \\
\hline
\end{tabular}




\begin{tabular}{|c|c|c|c|}
\hline Shopping Washer Picture & WINDOW $^{1}$ & .75 & +1.34 \\
\hline Blank White Lines & PAPER $^{2}$ & .80 & +1.56 \\
\hline Stick Light Birthday & CANDLE $^{2}$ & .80 & +1.69 \\
\hline Sore Shoulder Sweat & COLD $^{1}$ & .90 & +2.31 \\
\hline
\end{tabular}

${ }^{1}$ From RAT, Form 1 of Mednick \& Mednick (1967).

${ }^{2}$ From Bowers, Regehr, Balthazard, \& Parker (1990).

${ }^{3}$ Modified from Bowers et al.(1990). 


\section{REFERENCES}

Abramson, L. Y., Seligman, M. E., \& Teasdale, J. D. (1978). Learned helplessness in humans: Critique and reformulation. Journal of Abnormal Psychology, 87(1), 49-74. doi:10.1037/0021-843X.87.1.49

Aiken, L. S., \& West, S. G. (1991). Multiple regression: Testing and interpreting interactions. Sage Publications, Inc.

Anderson, C. A. (1983). Motivational and performance deficits in interpersonal settings: The effect of attributional style. Journal of Personality and Social Psychology, 45(5), 11361147. doi:10.1037/0022-3514.45.5.1136

Bandura, A. (1986). Social foundations of thought and action: A social cognitive theory. Englewood Cliffs, NJ: Prentice-Hall.

Bandura, A. (1977). Self-efficacy: Toward a unifying theory of behavioral change. Psychological Review, 84, 191-215.

Baumann, D. J., Cialdini, R. B., \& Kendrick, D. T. (1981). Altruism as hedonism: Helping and self-gratification as equivalent responses. Journal of Personality and Social Psychology, 40(6), 1039-1046. doi:10.1037/0022-3514.40.6.1039

Baumeister, R. F. (1991). Meanings of life. New York: Guilford Press.

Baumeister, R. F., DeWall, C. N., Ciarocco, N. J., \& Twenge, J. M. (2005). Social exclusion impairs self-regulation. Journal of Personality and Social Psychology, 88(4), 589.

Baumeister, R. F., \& Leary, M. R. (1995). The need to belong: Desire for interpersonal attachments as a fundamental human motivation. Psychological Bulletin, 117(3), 497-529. doi:10.1037/0033-2909.117.3.497

Beal, D. J., Cohen, R. R., Burke, M. J., \& McLendon, C. L. (2003). Cohesion and performance in groups: A meta-analytic clarification of construct relations. Journal of Applied Psychology, 88(6), 989-1004. doi:10.1037/0021-9010.88.6.989

Beck, A. T., \& Young, J. E. (1978). College blues. Psychology Today, 12(4), 80-95.

Bell, R. A., Roloff, M. E., Van Camp, K., \& Karol, S. H. (1990). Is it lonely at the top?: Career success and personal relationships. Journal of Communication, 40(1), 9-23.

Belsley, D. A., Kuh, E., \& Welsch, R. E. (1980). Regression diagnostics: Identifying influential data and sources of collinearity. New York: John Wiley \& Sons. 
Bernstein, E. (2013, Nov 4, 2013). When being alone turns into loneliness, there are ways to fight back. Wall Street Journal (Online). Retrieved from http://search.proquest.com/docview/1448296216? accountid=14244

Blau, P. M. (1964). Exchange and power in social life. New York: Wiley.

Borman, W. C., \& Motowidlo, S. J. (1997). Task performance and contextual performance: The meaning for personnel selection research. Human Performance, 10(2), 99. Retrieved from https://auth.lib.unc.edu/ezproxy_auth.php?url=http://search.ebscohost.com/login.aspx?direct $=$ true $\& d b=s 3 h \& A N=7309119 \&$ site $=$ ehost-live $\&$ scope $=$ site

Brewer, M. B., \& Gardner, W. (1996). Who is this" we"? levels of collective identity and self representations. Journal of Personality and Social Psychology, 71(1), 83.

Cacioppo, J. T., Fowler, J. H., \& Christakis, N. A. (2009). Alone in the crowd: The structure and spread of loneliness in a large social network. Journal of Personality and Social Psychology, 97(6), 977-991. doi:10.1037/a0016076

Cacioppo, J. T., Hawkley, L. C., Crawford, L. E., Ernst, J. M., Burleson, M. H., Kowalewski, R., Berntson, G. (2002). Loneliness and health: Potential mechanisms. Psychosomatic Medicine, 64(3), 407-417.

Cacioppo, J. T., Hawkley, L. C., Ernst, J. M., Burleson, M., Berntson, G. G., Nouriani, B., \& Spiegel, D. (2006). Loneliness within a nomological net: An evolutionary perspective. Journal of Research in Personality, 40(6), 1054-1085. doi:10.1016/j.jrp.2005.11.007

Cacioppo, J. T., \& Patrick, W. (2008). Loneliness: Human nature and the need for social connection. New York: W. W. Norton \& Company.

Cacioppo, J. T., Cacioppo, S., \& Boomsma, D. I. (2014). Evolutionary mechanisms for loneliness. Cognition \& Emotion, (ahead-of-print), 1-19.

Cacioppo, J. T., Ernst, J. M., Burleson, M. H., McClintock, M. K., Malarkey, W. B., Hawkley, L. C., ... Berntson, G. G. (2000). Lonely traits and concomitant physiological processes: The MacArthur social neuroscience studies. International Journal of Psychophysiology, 35(23), 143-154. doi:http://dx.doi.org/10.1016/S0167-8760(99)00049-5

Capelli, P. (1999). The new deal at work: Managing the market-driven workforce. Boston, Massachusetts: Harvard Business School Press.

Caspi, A. A. (2006). Socially isolated children 20 years Later: Risk of cardiovascular disease. Archives of Pediatrics \& Adolescent Medicine, 160(8), 805.

Christian, M. S., \& Ellis, A. P. J. (2011). Examining the effects of sleep deprivation on workplace deviance: A self-regulatory perspective. Academy of Management Journal, 54(5), 913-934. doi:10.5465/amj.2010.0179 
Cialdini, R. B., Darby, B. L., \& Vincent, J. E. (1973a). Transgression and altruism: A case for hedonism. Journal of Experimental Social Psychology, 9(6), 502-516.

Cialdini, R. B., Darby, B. L., \& Vincent, J. E. (1973b). Transgression and altruism: A case for hedonism. Journal of Experimental Social Psychology, 9(6), 502-516. doi:10.1016/00221031(73)90031-0

Cialdini, R. B., \& Kenrick, D. T. (1976). Altruism as hedonism: A social development perspective on the relationship of negative mood state and helping. Journal of Personality and Social Psychology, 34(5), 907-914. doi:10.1037/0022-3514.34.5.907

Cohen, J. (1988). Statistical power analysis for the behavioral sciences. Psychology Press.

Conoley, C. W., \& Garber, R. A. (1985). Effects of reframing and self-control directives on loneliness, depression, and controllability. Journal of Counseling Psychology, 32(1), 139.

Crocker, J., \& Wolfe, C. T. (2001). Contingencies of self-worth. Psychological Review, 108(3), 593.

Cutrona, C. E. (1982). Transition to college: Loneliness and the process of social adjustment. In L. A. Peplau, \& D. Perlman (Eds.), Loneliness: A sourcebook of current theory, research, and therapy (pp. 291-309). New York: Wiley-Interscience.

de Jong-Gierveld, J., \& Raadschelders, J. (1982). Types of loneliness. In L. A. Peplau, \& D. Perlman (Eds.), Loneliness: A sourcebook of current theory, research and therapy (pp. 105-122). New York: Wiley-Interscience.

Donnellan, M. B., Oswald, F. L., Baird, B. M., \& Lucas, R. E. (2006). The mini-IPIP scales: Tiny-yet-effective measures of the big five factors of personality. Psychological Assessment, 18(2), 192-203. doi:10.1037/1040-3590.18.2.192

Dovidio, J. F., Piliavin, J. A., Schroeder, D. A., \& Penner, L. (2006). The social psychology of prosocial behavior. Mahwah, New Jersey: Lawrence Erlbaum Associates Publishers.

Evans, J. M., \& Gilliland, S. W. (2006). Unfair customer treatment and managerial trust: Employee reactions to unfair customer policy and treatment. Annual Meeting of the Academy of Management, Atlanta.

Farrell, S. K., \& Finkelstein, L. M. (2007). Organizational citizenship behavior and gender: Expectations and attributions for performance. North American Journal of Psychology, 9(1), 81-96.

Faul, F., Erdfelder, E., Lang, A., \& Buchner, A. (2007). G* power 3: A flexible statistical power analysis program for the social, behavioral, and biomedical sciences. Behavior Research Methods, 39(2), 175-191. 
Fiske, S. T. (2004). Social beings: A core motives approach to social psychology. John Wiley $\&$ Sons, Inc.

Fromm-Reichman, F. (1959). Loneliness. Psychiatry, 22, 1-15.

Gardner, W. L., Pickett, C. L., \& Brewer, M. B. (2000). Social exclusion and selective memory: How the need to belong influences memory for social events. Personality and Social Psychology Bulletin, 26(4), 486-496. doi:10.1177/0146167200266007

Gardner, W. L., Pickett, C. L., Jefferis, V., \& Knowles, M. (2005). On the outside looking in: Loneliness and social monitoring. Personality and Social Psychology Bulletin, 31(11), 1549-1560. doi:10.1177/0146167205277208

George, J. M., \& Jones, G. R. (1997). Organizational spontaneity in context. Human Performance, 10(2), 153-170.

George, J. M., \& Brief, A. P. (1992). Feeling good-doing good: A conceptual analysis of the mood at work-organizational spontaneity relationship. Psychological Bulletin, 112(2), 310329. doi:10.1037/0033-2909.112.2.310

Goldmsith, S. K., Pellmar, T. C., Kleinman, A. M., \& Bunney, W. E. (2002). Reducing suicide: A national imperative. Washington, D.C.: National Academy Press.

Hawkley, L. C., \& Cacioppo, J. T. (2010). Loneliness matters: A theoretical and empirical review of consequences and mechanisms. Annals of Behavioral Medicine, 40(2), 218-227.

Hawkley, L. C., Preacher, K. J., \& Cacioppo, J. T. (2010). Loneliness impairs daytime functioning but not sleep duration. Health Psychology, 29(2), 124-129. doi: $10.1037 / \mathrm{a} 0018646$

Hawkley, L. C., Browne, M. W., \& Cacioppo, J. T. (2005). How can I connect with thee? let me count the ways. Psychological Science, 16(10), 798-804.

Hayes, A. F., \& Matthes, J. (2009). Computational procedures for probing interactions in OLS and logistic regression: SPSS and SAS implementations. Behavior Research Methods, 41(3), 924-936.

Heinrich, L. A., \& Gullone, E. (2006). The clinical significance of loneliness: A literature review. Clinical Psychology Review, 26(6), 695-718. doi:10.1016/j.cpr.2006.04.002

Hofmann, D. A., Morgeson, F. P., \& Gerras, S. J. (2003). Climate as a moderator of the relationship between leader-member exchange and content specific citizenship: Safety climate as an exemplar. Journal of Applied Psychology, 88(1), 170-178. doi:10.1037/00219010.88.1.170 
Holt-Lunstad, J., Smith, T. B., \& Layton, J. B. (2010). Social relationships and mortality risk: A meta-analytic review. PLoS Medicine, 7(7), e1000316.

Horowitz, L. M., French, R. d., \& Anderson, C. A. (1982). The prototype of a lonely person. In L. A. Peplau, \& D. Perlman (Eds.), Loneliness: A sourcebook of current theory, research and therapy (pp. 183-205). New York: Wiley-Interscience.

Hughes, M. E., Waite, L. J., Hawkley, L. C., \& Cacioppo, J. T. (2004). A short scale for measuring loneliness in large surveys results from two population-based studies. Research on Aging, 26(6), 655-672.

Johnson, P. O., \& Neyman, J. (1936). Tests of certain linear hypotheses and their application to some educational problems. Statistical Research Memoirs.

Kelly, K. M. (2001). Individual differences in reactions to rejection. In M. R. Leary (Ed.), Interpersonal rejection (pp. 291-315). New York: Oxford University Press.

Keltner, D., \& Gross, J. J. (1999). Functional accounts of emotions. Cognition \& Emotion, 13(5), 467-480. doi:10.1080/026999399379140

Keltner, D., \& Haidt, J. (1999). Social functions of emotions at four levels of analysis. Cognition \& Emotion, 13(5), 505-521. doi:10.1080/026999399379168

Kronmal, R. A. (1993). Spurious correlation and the fallacy of the ratio standard revisited. Journal of the Royal Statistical Society, Series A (Statistics in Society), 156(3), 379-392. Retrieved from http://www.jstor.org/stable/2983064

Lau, S., \& Gruen, G. E. (1992). The social stigma of loneliness: Effect of target person's and perceiver's sex. Personality and Social Psychology Bulletin, 18(2), 182-189.

Lazarus, R. S. (1991a). Emotion and adaptation. Oxford University Press New York.

Lazarus, R. S. (1991b). Cognition and motivation in emotion. American Psychologist, 46(4), 352-367. doi:10.1037/0003-066X.46.4.352

Leary, M. R., Kelly, K. M., Cottrell, C. A., \& Schreindorfer, L. S. (2013). Construct validity of the need to belong scale: Mapping the nomological network. Journal of Personality Assessment, 95(6), 610-624.

LeBreton, J. M., \& Senter, J. L. (2008). Answers to 20 questions about interrater reliability and interrater agreement. Organizational Research Methods, 11(4), 815-852.

doi:10.1177/1094428106296642

Manucia, G. K., Baumann, D. J., \& Cialdini, R. B. (1984). Mood influences on helping: Direct effects or side effects? Journal of Personality and Social Psychology, 46(2), 357-364. doi:10.1037/0022-3514.46.2.357 
Masi, C. M., Chen, H., Hawkley, L. C., \& Cacioppo, J. T. (2011). A meta-analysis of interventions to reduce loneliness. Personality and Social Psychology Review, 15(3), 219266. doi: $10.1177 / 1088868310377394$

Maslow, A. H. (1943). A theory of human motivation. Psychological Review, 50(4), 370.

McAuley, E., Duncan, T. E., \& Russell, D. W. (1992). Measuring causal attributions: The revised causal dimension scale (CDSII). Personality and Social Psychology Bulletin, 18(5), 566-573. doi:10.1177/0146167292185006

McPherson, M., Smith-Lovin, L., \& Brashears, M. E. (2006). Social isolation in america: Changes in core discussion networks over two decades. American Sociological Review, 71(3), 353-375. Retrieved from http://www.jstor.org/stable/30038995

McWhirter, B. T. (1990). Loneliness : A review of current literature, with implications for counseling and research. Journal of Counseling and Development, 68(4), 417-422.

Mellor, D., Stokes, M., Firth, L., Hayashi, Y., \& Cummins, R. (2008). Need for belonging, relationship satisfaction, loneliness, and life satisfaction. Personality and Individual Differences, 45(3), 213-218. doi:http://dx.doi.org/10.1016/j.paid.2008.03.020

Michela, J. L., Peplau, L. A., \& Weeks, D. G. (1982). Perceived dimensions of attributions for loneliness. Journal of Personality and Social Psychology, 43(5), 929-936. doi:10.1037/0022-3514.43.5.929

O'Reilly, C. A., \& Chatman, J. (1986). Organizational commitment and psychological attachment: The effects of compliance, identification, and internalization on prosocial behavior. Journal of Applied Psychology, 71(3), 492-499. doi:10.1037/0021-9010.71.3.492

Organ, D. W., \& Ryan, K. (1995). A meta-analytic review of attitudinal and dispositional predictors of organizational citizenship behavior. Personnel Psychology, 48(4), 775-802.

Ozcelik, H., \& Barsade, S. (2011, January). Work loneliness and employee performance. In Academy of Management Proceedings (Vol. 2011, No. 1, pp.1-6). Academy of Management.

Peplau, L. A., \& Perlman, D. (1982). Perspectives on loneliness. In L. A. Peplau, \& D. Perlman (Eds.), Loneliness: A sourcebook of current theory, research and therapy (pp. 1-18). New York: Wiley-Interscience.

Peplau, L. A. (1985). Loneliness research: Basic concepts and findings. In I. G. Sarason, \& B. R. Sarason (Eds.), Social support: Theory, research and applications (pp. 269-286). Boston: Nijhoff. 
Peplau, L. A., Russell, D. W., \& Heim, M. (1979). The experience of loneliness. In I. H. Frieze, D. Bar-Tal \& J. S. Carroll (Eds.), New approaches to social problems (pp. 53-78). San Francisco: Jossey-Bass Publishers.

Pickett, C. L., \& Gardner, W. L. (2005). The social monitoring system: Enhanced sensitivity to social cues as an adaptive response to social exclusion. In K. D. Williams, J. P. Forgas \& W. von Hippel (Eds.), The social outcast: Ostracism, social exclusion, rejection, and bullying (pp. 213-226). New York, NY: Psychology Press.

Pickett, C. L., Gardner, W. L., \& Knowles, M. (2004). Getting a cue: The need to belong and enhanced sensitivity to social cues. Personality and Social Psychology Bulletin, 30(9), 1095-1107. doi:10.1177/0146167203262085

Podsakoff, P. M., MacKenzie, S. B., Paine, J. B., \& Bachrach, D. G. (2000). Organizational citizenship behaviors: A critical review of the theoretical and empirical literature and suggestions for future research. Journal of Management, 26(3), 513-563.

Podsakoff, P. M., MacKenzie, S. B., Lee, J., \& Podsakoff, N. P. (2003). Common method biases in behavioral research: A critical review of the literature and recommended remedies.

Journal of Applied Psychology, 88(5), 879-903. doi:10.1037/0021-9010.88.5.879

Putnam, R. (2000). Bowling alone: The collapse and revival of American community. Simon and Schuster.

Rich, B. L., Lepine, J. A., \& Crawford, E. R. (2010). Job engagement: Antecedents and effects on job performance. Academy of Management Journal, 53(3), 617-635.

doi:10.5465/AMJ.2010.51468988

Rokach, A. (2012). Loneliness updated: An introduction. The Journal of Psychology, 146(1-2), 1-6.

Rotenberg, K. J., \& Kmill, J. (1992). Perception of lonely and non-lonely persons as a function of individual differences in loneliness. Journal of Social and Personal Relationships, 9(2), 325-330.

Rubenstein, C. M., \& Shaver, P. (1982). The experience of loneliness. In L. A. Peplau, \& D. Perlman (Eds.), Loneliness: A sourcebook of current theory, research, and therapy (pp. 206-223). New York: Wiley-Interscience.

Russell, D. W. (1996). UCLA loneliness scale (version 3): Reliability, validity, and factor structure. Journal of Personality Assessment, 66(1), 20. Retrieved from https://auth.lib.unc.edu/ezproxy_auth.php?url=http://search.ebscohost.com/login.aspx?direct $=$ true $\& \mathrm{db}=\mathrm{a} 9 \mathrm{~h} \& \mathrm{AN}=6380089 \&$ site $=$ ehost - live $\&$ scope $=$ site 
Russell, D. W., Cutrona, C. E., Rose, J., \& Yurko, K. (1984). Social and emotional loneliness an examination of weiss typology of loneliness. Journal of Personality and Social Psychology, 46(6), 1313-1321. doi:10.1037/0022-3514.46.6.1313

Russell, D. W., Peplau, L. A., \& Cutrona, C. E. (1980). The revised UCLA loneliness scale concurrent and discriminant validity evidence. Journal of Personality and Social Psychology, 39(3), 472-480. doi:10.1037/0022-3514.39.3.472

Ryan, R. M., \& Deci, E. L. (2000). Self-determination theory and the facilitation of intrinsic motivation, social development, and well-being. American Psychologist, 55(1), 68-78. doi:10.1037/0003-066X.55.1.68

Schwarz, N. (2001). Feelings as information: Implications for affective influences on information processing. Theories of Mood and Cognition: A User's Guidebook, 159-176.

Shiovitz-Ezra, S., \& Ayalon, L. (2010). Situational versus chronic loneliness as risk factors for all-cause mortality. International Psychogeriatrics, 22(3), 455.

Spitzberg, B. H., \& Canary, D. J. (1985). Loneliness and relationally competent communication. Journal of Social and Personal Relationships, 2(4), 387-402. doi:10.1177/0265407585024001

Sullivan, H. S. (1953). The interpersonal theory of psychiatry. New York: Norton.

Tabachnick, B. G., \& Fidell, L., S. (2007). Using multivariate statistics (5th ed.). Boston: Pearson Education, Inc.

Teppers, E., Klimstra, T. A., Damme, C. V., Luyckx, K., Vanhalst, J., \& Goossens, L. (2013). Personality traits, loneliness, and attitudes toward aloneness in adolescence. Journal of Social and Personal Relationships, 30(8), 1045-1063. doi:10.1177/0265407513481445

Tiedens, L. Z., \& Linton, S. (2001). Judgment under emotional certainty and uncertainty: The effects of specific emotions on information processing. Journal of Personality and Social Psychology, 81(6), 973-988. doi:10.1037/0022-3514.81.6.973

Tilvis, R. R. S. (2004). Predictors of cognitive decline and mortality of aged people over a 10year period. The Journals of Gerontology.Series A, Biological Sciences and Medical Sciences, 59(3), M268-M274.

Twenge, J. M., Baumeister, R., Tice, D., \& Stucke, T. (2001). If you can't join them, beat them: Effects of social exclusion on aggressive behavior. Journal of Personality and Social Psychology, 81(6), 1058-1069. doi:10.1037/0022-3514.81.6.1058

Vespa, J., Lewis, J. M., \& Kreider, R. M. (2013). America's families and living arrangements: 2012. ( No. P20-570).U. S. Census Bureau. 
Vroom, V. (1964). The motivation to work. New York: Wiley.

Watson, D., Clark, L. A., \& Tellegen, A. (1988). Development and validation of brief measures of positive and negative affect: The PANAS scales. Journal of Personality and Social Psychology, 54(6), 1063-1070. doi:10.1037/0022-3514.54.6.1063

Weiner, B. (1974). Achievement motivation and attribution theory. Morristown, N.J.: General Learning Press.

Weiner, B. (1979). A theory of motivation for some classroom experiences. Journal of Educational Psychology, 71(1), 3-25. doi:10.1037/0022-0663.71.1.3

Weinstein, N., \& Ryan, R. M. (2010). When helping helps: Autonomous motivation for prosocial behavior and its influence on well-being for the helper and recipient. Journal of Personality and Social Psychology, 98(2), 222.

Weiss, R. S. (1973). Loneliness: The experience of emotional and social isolation. Cambridge, MA: The MIT Press.

Weiss, R. F., Boyer, J. L., Lombardo, J. P., \& Stich, M. H. (1973). Altruistic drive and altruistic reinforcement. Journal of Personality and Social Psychology, 25(3), 390-400. doi: $10.1037 / \mathrm{h} 0034235$

Weyant, J. M. (1978). Effects of mood states, costs, and benefits on helping. Journal of Personality and Social Psychology, 36(10), 1169-1176. doi:10.1037/0022-3514.36.10.1169

Wildschut, T., Sedikides, C., Arndt, J., \& Routledge, C. (2006). Nostalgia: Content, triggers, functions. Journal of Personality and Social Psychology, 91(5), 975-993. doi:10.1037/0022-3514.91.5.975

Williams, R. A., Hagerty, B. M., Yousha, S. M., Horrocks, J., Hoyle, K. S., \& Liu, D. (2004). Psychosocial effects of the boot strap intervention in navy recruits. Military Medicine, 169(10), 814-820. Retrieved from https://auth.lib.unc.edu/ezproxy_auth.php?url=http://search.ebscohost.com/login.aspx?direct $=$ true $\& \mathrm{db}=\mathrm{c} 9 \mathrm{~h} \& \mathrm{AN}=14704220 \&$ site $=$ ehost-live $\&$ scope $=$ site

Wilson, C., \& Moulton, B. (2010). Loneliness among older adults: A national survey of adults 45+. Knowledge Networks and Insight Policy Research, Washington, DC: AARP.

Young, J. E. (1982). Loneliness, depression and cognitive therapy: Theory and application. In L. A. Peplau, \& D. Perlman (Eds.), Loneliness: A sourcebook of current theory, research, and therapy (pp. 379-405). New York: Wiley-Interscience.

Zhou, X., Sedikides, C., Wildschut, T., \& Gao, D. (2008). Counteracting loneliness: On the restorative function of nostalgia. Psychological Science, 19(10), 1023-1029. doi:10.1111/j.1467-9280.2008.02194.x 